Risk Stratification Guidelines

\title{
e Evidence-Based Risk Mitigation and Stratification during COVID-19 for Return to Interventional Pain Practice: American Society of Interventional Pain Physicians (ASIPP) Guidelines
}

\author{
Shalini Shah, MD; Sudhir Diwan, MD²; Amol Soin, MD; Kartic Rajput, MD, ${ }^{3}{ }^{4}$; \\ Amit Mahajan, MBBS5; Laxmaiah Manchikanti, MD; Alan D. Kaye, MD, PhD7; \\ Joshua A. Hirsch, MD; ${ }^{8}$ and Christopher Gharibo, MD ${ }^{9}$
}

From: ${ }^{2}$ University of California Irvine, Orange, CA; ${ }^{2}$ Advanced Spine on Park Avenue and Albert Einstein College of Medicine, New York, NY; 3Ohio Pain Clinic, Dayton, $\mathrm{OH}$ and Wright State University, Dayton, $\mathrm{OH} ;{ }^{4}$ Sutter

Gould Medical Foundation Stockton, CA; ${ }^{\text {Y }}$ ale School of Medicine, New Haven, CT; ${ }^{\circ}$ Pain Management Centers of America, Paducah, KY; ' $\mathrm{LSU}$ School of Medicine, Shreveport, LA and New Orleans, LA and Tulane School of Medicine, New Orleans, LA ${ }^{8}$ Massachusetts General Hospital and Harvard Medical School, Boston, MA; ${ }^{\mathrm{N} Y U}$ Langone Health and NYU School of Medicine, New York, NY

Address Correspondence: Shalini Shah, MD

Department of Anesthesiology \& Perioperative Care

University of California Irvine 101 The City Drive South Building 53 Orange, CA 92868

E-mail: shahshalini@gmail.com

Disclaimer: There was no external funding in the preparation of this manuscript.

Conflict of interest: Each author certifies that he or she, or a member of his or her immediate family, has no commercial association (i.e., consultancies, stock ownership, equity interest, patent/licensing arrangements, etc.) that might pose a conflict of interest in connection with the submitted manuscript.

Manuscript received: 05-14-2020 Accepted for publication: 06-12-2020

Free full manuscript: www.painphysicianjournal.com
Background: Chronic pain patients require continuity of care even during the COVID-19 pandemic, which has drastically changed healthcare and other societal practices. The American Society of Interventional Pain Physicians (ASIPP) has created the COVID-ASIPP Risk Mitigation and Stratification (COVID-ARMS) Return to Practice Task Force in order to provide guidance for safe and strategic reopening.

Objectives: The aims are to provide education and guidance for interventional pain specialists and their patients during the COVID-19 pandemic that minimizes COVID-related morbidity while allowing a return to interventional pain care.

Methods: The methodology utilized included the development of objectives and key questions with utilization of trustworthy standards, appropriate disclosures of conflicts of interest, as well as a panel of experts from various regions, specialities, and groups. The literature pertaining to all aspects of COVID-19, specifically related to epidemiology, risk factors, complications, morbidity and mortality, and literature related to risk mitigation and stratification were reviewed. The principles of best-evidence synthesis of available literature and grading for recommendations as described by the Agency for Healthcare Research and Quality (AHRQ), typically utilized in ASIPP guideline preparation, was not utilized in these guidelines due to the limitation based on lack of available literature on COVID-19, risk mitigation and stratification. Consequently, these guidelines are considered evidence-informed with the incorporation of the best-available research and practice knowledge.

Results: Numerous risk factors have emerged that predispose patients to contracting COVID-19 and/or having a more severe course of the infection. COVID-19 may have mild symptoms, be asymptomatic, or may be severe and life-threatening. Older age and certain comorbidities, such as underlying pulmonary or cardiovascular disease, have been associated with worse outcomes. In pain care, COVID-19 patients are a heterogeneous group with some individuals relatively healthy and having only a short course of manageable symptoms, while others become critically ill. It is necessary to assess patients on a case-by-case basis and craft individualized care recommendations. A COVID-19 ARMS risk stratification tool was created to quickly and objectively assess patients. Interventional pain specialists and their patients may derive important benefits from evidenceinformed risk stratification, protective strategies to prevent infection, and the gradual resumption of treatments and procedures to manage pain.

Limitations: COVID-19 was an ongoing pandemic at the time these recommendations were developed. The pandemic has created a fluid situation in terms of evidence-informed guidance. As more and better evidence is gathered, these recommendations may be modified.

Conclusions: Chronic pain patients require continuity of care, but during the time of the COVID-19 pandemic, steps must be taken to stratify risks and protect patients from possible infection to safeguard them from COVID-19-related illness and transmitting the disease to others. Pain specialists should optimize telemedicine encounters with pain patients, be cognizant of risks 
of COVID-19 morbidity, and take steps to evaluate risk-benefit on a case-by-case basis. Pain specialists may return to practice with lower-risk patients and appropriate safeguards.

Key words: Cardiovascular disease, COVID-19, interventional pain management, COVID risk factors, diabetes, hypertension, interventional pain care, novel coronavirus, obesity, SARS-nCoV2, steroids

\subsection{InTRODUCTION}

The COVID-19 pandemic has created unprecedented challenges to society in general, and the healthcare system, in particular. In the United States, a prerequisite for health care facilities to return to performing interventional pain procedures is robust testing for active infection for at-risk healthcare professionals. This may also include emerging tests for antibodies (1). It should be noted that because conditions across the United States are highly variable, with COVID-19 outbreaks ranging from mild to severe, state and local authorities have tailored their recommendations to meet their local circumstances. The federal Opening Up America Again program in the United States is a three-phase, data-driven approach guided by public health experts which, among other things, provides guidance for healthcare systems (1). Among the core responsibilities at the state level for preparedness for healthcare systems are the rapid and sufficient provision of personal protective equipment (PPE) and critical medical equipment to handle increases in need, and the ability to surge the capacity of intensive care units (ICUs), as needed (1).

Chronic pain afflicts at least 50 million Americans, of whom about 20 million have "high impact" chronic pain with functional deficits (2). The impact of chronic spinal pain on healthcare is enormous. Studies relating to the burden of diseases, disability, and health care expenses showed low back pain ranked number one, and that expenses increased, along with disability (3). Multiple modalities of treatments have been utilized in managing chronic pain, specifically of spinal pain, with inclusion of various modes of conservative therapy, including non-steroidal anti-inflammatory agents, anti-epileptic drugs, and opioids, along with multiple interventional techniques, in addition to surgical interventions (4-10). All treatments have been affected during this pandemic, including surgical interventions. Multiple publications have described issues related to orthopedic and plastic surgery, and its delays and subsequent economic impact $(7,8)$. Guidelines also have been published with recommendations for resuming elective surgery (8) and caring for patients with pain during the
COVID-19 pandemic with consensus recommendations (9). In addition to interventional techniques, the role of opioids has been discussed, including the side effects, withdrawals, and opioid-related deaths (11-14). Also, the COVID-19 pandemic has introduced additional problems with an epidemic in the midst of a pandemic related to opioid use disorders, and the fear of withdrawal fueling purchase of over the street drugs and increasing abuse patterns without appropriate management (14).

While telehealth has been promoted to manage the opioid crisis, reopening of the interventional pain management practices has not been discussed and no such recommendations are available except for classification of procedures as emergent, urgent, and elective. The Centers for Disease Control and Prevention (CDC) has provided instructions for elective surgeries, along with their restrictions. Thus, chronic pain patients under the care of interventional pain specialists require ongoing care, procedures, and support more than ever during this time and may need special education to mitigate their risk for infection and to decrease the risk of COVID-associated morbidity should they contract the virus.

As clinicians, politicians, and the healthcare system navigate the COVID-19 pandemic, it is important to be aware of what has been called "the distraction effect," namely the ability of COVID-19 to overshadow all other health concerns to the point that there are negative effects on the health and psychological equilibrium of patients as well as causing excessive expenditures to the healthcare system. It is clear that overlooking routine care for chronic pain patients can have negative impacts on health, well-being, emotional stability, function, and quality of life (15). Pain specialists must balance the needs for pain control against reasonable concern and precautions related to the SARS-nCoV-2 virus associated with COVID-19.

Multiple guidelines have been published by the American Society of Interventional Pain Physicians (ASIPP) in performing various types of interventional techniques, regenerative medicine, opioids in chronic 
non-cancer pain, antithrombotic therapy, sedation, and facet joint interventions (4-6). Thus, ASIPP has been at the forefront of guideline development for the safe and responsible use of interventional techniques and opioids (4-6). ASIPP's burnout survey also showed startling results (16). Operations have been impacted by $98 \%$ of the members responding with $19 \%$ closing their offices, $77 \%$ utilizing telemedicine for evaluation and management services with $60 \%$ completely stopping performance of interventional procedures. Almost a quarter of the membership was performing procedures at a minimal volume of less than $20 \%$ and a few members were performing between $20 \%$ and $50 \%$ of the previous levels. Overall, the results seem to be that interventional pain management procedures may have been performed at a total of $10 \%$ of the baseline level, or even lower. In addition, $54 \%$ of the members responding showed that they have been burnt out due to economic physical and psychological effect of COVID-19. In contrast, a previous survey performed in 2016 of members of ASIPP showed burnout among physicians of $60.4 \%$.

Consequently, to better serve chronic pain patients in this challenging time of pandemic, the ASIPP established a "COVID-ARMS Return to Practice" Task Force to develop possible strategies to minimizes risks to clinicians and providers.

\subsection{Methods}

Chronic pain is a complex and multifactorial disease process with numerous treatment modalities applied in the management of the problem, and the growing social and economic costs continue to influence medical decision making. Interventional techniques and opioids are the mainstays of treatment while multiple other adjuvant modalities are provided in managing chronic pain by interventional pain physicians.

\subsection{Rationale}

Interventional pain management has been defined as the discipline of medicine devoted to the diagnosis and treatment of pain related disorders principally with the application of interventional techniques in managing subacute, chronic, persistent, and intractable pain, independently or in conjunction with other modalities of treatment (www.cms.hhs.gov/transmittals/Downloads/r1779b3.pdf Accessed 5/28/2020).. Interventional pain management techniques have been defined as minimally invasive procedures including percutaneous precision needle placement of drugs in targeted areas or ablation of targeted nerves; surgical techniques such as laser and endoscopic discectomy; and the placement of intrathecal infusion pumps and spinal cord stimulators for the diagnosis and management of chronic, persistent, or intractable pain (http://www.medpac. gov/documents/reports/december-2001-report-to-thecongress-paying-for-interventionalpain-services-in-ambulatory-settings.pdf?sfvrsn=0 Accessed 5/28/2020).

\subsection{Objectives}

The ASIPP COVID-ARMS Return to Practice Task Force was established to provide a context and strategy for the reopening of interventional pain practices. Fundamental to this task are the over-arching considerations of risk mitigation and risk stratification. Risk mitigation may be defined as taking specific steps in order to reduce harms to patients, healthcare professional, and the healthcare system. Thus, risk mitigation involves identification and assessment of risk factors, review of the literature, data analysis, training and education, and organizational responses to events. Stratification refers to the ability to triage or rank risks relative to each other. The COVID-ARMS Task Force sought to offer guidance that was not overly prescriptive, in that the best care is provided when careful clinical judgment is exercised on a case-by-case basis. A COVID-ARMS scoring system was created to rapidly and objectively help risk-stratify patients.

Clinicians must base their decisions on an assessment of individual risks versus benefits and understand that, ultimately, these recommendations are dynamic and situational. As more evidence and elucidation of the SARS-nCoV-2 virus emerge, more precise recommendations may follow. Furthermore, recommendations that are appropriate in one setting and location may be inappropriate for other settings. In particular with COVID-19, it is important for interventional pain specialists to take a localized approach to resuming their practice.

In order to resume interventional pain practice, it is important to stratify or rank patients for their relative risk of both contracting COVID-19 or having a poor outcome in the event of infection. A risk stratification scoring system has been developed to provide a rapid objective assessment of individual patients.

\subsection{Adherence to Trustworthy Standards}

In preparation of these guidelines for risk mitigation/stratification during COVID-19 for return to interventional pain practice, the standards from the 
Institute of Medicine (IOM) and the National Guideline Clearinghouse Extent Adherence to Trustworthy Standards (NEATS) were followed (17-19). The NEATS instrument was developed and tested as a tool to be used by the trained staff at the Agency for Healthcare Research and Quality (AHRQ) National Guideline Clearinghouse to provide assessment focused on adherence.

\subsubsection{Disclosure of Guideline Funding Source}

Comprehensive evidence-informed guidelines for risk mitigation/stratification during COVID-19 for return to interventional pain practice were commissioned, prepared, edited, and endorsed by ASIPP without external funding.

\subsubsection{Disclosure and Management of Financial Conflicts of Interests}

Potential conflicts of interest for all panel members within the last 5 years were evaluated prior to the finalizing of these guidelines. Conflicts of interests extended beyond financial relationships, including personal experience, practice patterns, academic interests, and promotions. The panel members with potential conflicts were recused from discussion or preparation of the guidelines in which they had conflicts of interest, and these members agreed not to discuss any aspect of a given guideline with the related industry before data publication.

\subsubsection{Composition of Guideline Development Group}

A panel of experts in interventional techniques, opioid therapy and administrative expertise from various medical fields, convened by ASIPP, reviewed the evidence and formulated recommendations for risk mitigation/stratification during COVID-19 for return to interventional pain practice. Overall, the panel provided a broad representation of academic and non-academic clinical practitioners with interest and expertise in interventional pain management.

\subsection{Evidence Review}

These guidelines were developed utilizing consensus among the panel members after they had reviewed all published literature concerning the use and safety of interventional techniques during and after the COVID-19 pandemic. The recommendations have been developed using principles of best-evidence synthesis developed by the Cochrane Review, incorporating multiple guidelines modified by ASIPP (20). Due to lack of RCTs or even observational studies related to interventional pain management, due to the nature of the subject and ongoing evolutionary changes, in this manuscript, evidence-informed strategy was utilized instead of evidence-based strategy. Evidence-based medicine process relies on quantitative research studies that provide the highest levels of evidence for decisions about interventions and other aspects including diagnosis, side effects, and prevalence (21). However, evidence-based approach is also considered too restrictive and that decision-making for individual patients, for an organization, for a population, or on various subjects without substantial evidence and evolving in epidemiology must rely on additional forms of evidence that are much more inclusive and less rigid.

Some experts proposed that information used to make clinical decisions in clinical practice should include more than evidence collected with a singular goal of reducing bias in interventional research and should include a variety of sources of research information that addresses a wider range of goals (22). Thus, it has been suggested that clinicians add their own conventional wisdom and common sense in the form of knowledge gained from qualitative and sometimes quantitative studies. Even though, the term "evidence-informed" is used infrequently compared to evidence-based, the distinction and advantages have been clarified by Woodbury and Kuhnke (21). However, Miles and Loughlin (23) promoted using the term "evidence-informed" to indicate that the process be person-centered rather than focused on the signs of reducing the quantitative evidence, which, they claim has taken humanity out of clinical practice. Further, multiple international and national organizations promote the idea of evidenceinformed decision-making, such as World Health Organization (WHO) and the Canadian Institutes of Health Research refer to evidence-informed decision making (24). Even though some utilize evidence-based and evidence-informed interchangeably, more recently with a movement towards real world evidence, it appears that evidence-informed may be a more appropriate term with more flexibility regarding the nature of the evidence and its use. Thus, it may be considered that evidence-informed medicine extends beyond the definition of evidence-based medicine with inclusion of real world evidence in real world settings.

\subsubsection{Grading or Rating the Quality or Strength of Evidence}

The grading of evidence is based on randomized 
Table 1. Qualitative modified approach to grading of evidence.

\begin{tabular}{|l|l|l||}
\hline Level I & Strong & $\begin{array}{l}\text { Evidence obtained from multiple relevant high-quality randomized controlled trials for effectiveness } \\
\text { or } \\
\text { Evidence obtained from multiple relevant high quality observational studies or large case series for } \\
\text { assessment of preventive measures, adverse consequences, and effectiveness of other measures }\end{array}$ \\
\hline Level II & Moderate & $\begin{array}{l}\text { Evidence obtained from at least one relevant high-quality randomized controlled trial or multiple relevant } \\
\text { moderate or low-quality randomized controlled trials } \\
\text { or } \\
\text { Evidence obtained from at least 2 high-quality relevant observational studies or large case series for } \\
\text { assessment of preventive measures, adverse consequences, and effectiveness of other measures. }\end{array}$ \\
\hline Level III & Fair & $\begin{array}{l}\text { Evidence obtained from at least one relevant high-quality nonrandomized trial or observational study with } \\
\text { multiple moderate or low-quality observational studies } \\
\text { or } \\
\text { At least one high-quality relevant observational studies or large case series for assessment of preventive } \\
\text { measures, adverse consequences, and effectiveness of other measures. }\end{array}$ \\
\hline Level IV & Limited & $\begin{array}{l}\text { Evidence obtained from multiple moderate or low-quality relevant observational studies } \\
\text { or } \\
\text { Evidence obtained from moderate quality observational studies or large case series for assessment of } \\
\text { preventive measures, adverse consequences, and effectiveness of other measures. }\end{array}$ \\
\hline Level V & Consensus based & $\begin{array}{l}\text { Opinion or consensus of large group of clinicians and/or scientists for effectiveness as well as to assess } \\
\text { preventive measures, adverse consequences, and effectiveness of other measures. }\end{array}$ \\
\hline
\end{tabular}

Modified from: Manchikanti et al. A modified approach to grading of evidence. Pain Physician 2014; 17:E319-E325 (20).

controlled trials (RCTs), observational studies, and other clinical reports. In addition, systematic reviews and meta-analyses were utilized. The grading of evidence based on ASIPP guidelines is shown in Table 1 (20).

This grading system specifies levels of scientific evidence and offers an approach to grading the quality of evidence and secondarily the strength of recommendations. AHRQ has recommended a similar approach to the strength of a recommendation $(18,19)$.

\subsubsection{Rating or Grading the Strength of Recommendations}

IOM standards demand that for each recommendation, a rating of the strength of the recommendation related to benefits and harms, available evidence, and the confidence in the underlying evidence should be provided. To meet appropriate standards, the rating schemes recommended by NEATS were utilized as shown in Table 2 (18).

\subsection{RESULTS}

All the relevant studies were identified by search of multiple databases and mechanisms with the search focusing on COVID-19 related epidemiology, pathophysiology, complications, testing, and guidance on prevention in preoperative period, intraoperative period, and postoperative period of performing interventional techniques. Multiple manuscripts were iden- tified. There were no manuscripts available describing specific evidence-informed risk mitigation/stratification strategies during COVID-19 for return to interventional pain practices. However, due to the complex nature of the problem, in a pandemic setting without much guidance available, we were unable to apply evidenceinformed principles with grading of evidence and the strength of recommendations as described in the past (17-20).

We have utilized evidence-informed approach and provided recommendations.

\subsection{COVID-ARMS Stratification Tools}

Table 3 provides a rapid risk-stratification tool for determining the individual patient's risk factors. A flow chart showing recommendations for interventional pain management during the "return to practice" phase of the COVID-19 epidemic appears in Fig. 1.

\subsection{Specific Comorbidities}

The CDC surveyed Americans hospitalized for COVID-19 from March 1-28, 2020 ( $n=1,482$ ) in the COVID-NET survey and found a hospitalization rate of 4.6 per 100,000 population and observed that $90 \%$ of the patients hospitalized for COVID-19 had one or more underlying conditions, of which hypertension, obesity, chronic lung disease, type 2 diabetes, and cardiovascular disease were the most common. Age was 
Table 2. Guide for strength of recommendations.

\begin{tabular}{|l|l||}
\hline \multicolumn{3}{|l|}{ Rating for Strength of Recommendation } \\
\hline Strong & $\begin{array}{l}\text { There is high confidence that the recommendation reflects best practice. This is based on: a) strong evidence for a true net } \\
\text { effect (e.g., benefits exceed harms); b) consistent results, with no or minor exceptions; c) minor or no concerns about study } \\
\text { quality; and/or d) the extent the panelists' agreement. Other compelling considerations (discussed in the guideline's literature } \\
\text { review and analyses) may also warrant a strong recommendation. }\end{array}$ \\
\hline Moderate & $\begin{array}{l}\text { There is moderate confidence that the recommendation reflects best practice. This is based on: a) good evidence for a true } \\
\text { net effect (e.g. benefits exceed harms); b) consistent results, with minor and/or few exceptions; c) minor and/or few concerns } \\
\text { about study quality; and/or d) the extent of panelists' agreement. Other compelling considerations (discussed in the guideline's } \\
\text { literature review and analyses) may also warrant a moderate recommendation. }\end{array}$ \\
\hline Weak & $\begin{array}{l}\text { There is some confidence that the recommendation offers the best current guidance for practice. This is based on: a) limited } \\
\text { evidence for a true net effect (e.g., benefits exceed harms); b) consistent results, but with important exceptions; c) concerns } \\
\text { about study quality; and/or d) the extent of panelists' agreement. Other considerations (discussed in the guideline's literature } \\
\text { review and analyses) may also warrant a weak recommendation. }\end{array}$ \\
\hline
\end{tabular}

Source: National Guideline Clearinghouse Extent Adherence to Trustworthy Standards (NEATS) instrument (18).

Table 3. COVID-ARMS risk stratification of patients presenting for interventional pain procedures for decreasing morbidity of COVID-19 (points appear in brackets).

If Patient Residence status is Nursing Home or Assisted Living Facility or Incarceration during the past 30 days, consider as HIGH-RISK Patient. If not, follow below table for risk stratification.

\begin{tabular}{|c|c|c|c|}
\hline Risk Factor & Low Risk & Moderate Risk & High Risk \\
\hline Age (years) & $\begin{array}{c}\text { 45-64 years } \\
{[1]}\end{array}$ & $\begin{array}{c}\text { 65-74 years } \\
{[2]}\end{array}$ & $\begin{array}{c}\geq 75 \text { years } \\
{[3]}\end{array}$ \\
\hline Pulmonary & $\begin{array}{l}\text { None } \\
{[0]}\end{array}$ & $\begin{array}{l}\text { Mild intermittent asthma } \\
{[2]}\end{array}$ & $\begin{array}{c}\text { Chronic lung condition, i.e., moderate } \\
\text { to severe asthma, COPD } \\
{[3]}\end{array}$ \\
\hline Cardiovascular & $\begin{array}{c}\text { None } \\
{[0]}\end{array}$ & $\begin{array}{c}\mathrm{HTN} \text { or CAD } \\
{[2]}\end{array}$ & $\begin{array}{c}\text { HTN + CAD } \\
\text { HTN + CHF } \\
\text { HTN + CAD + CHF } \\
\text { CHF alone } \\
{[3]}\end{array}$ \\
\hline Obesity & $\begin{array}{c}\text { BMI 24.9-29.9 } \\
{[1]}\end{array}$ & $\begin{array}{c}\text { BMI 30.0-39.9 } \\
{[2]}\end{array}$ & $\begin{array}{c}\mathrm{BMI} \\
\quad[3]\end{array}$ \\
\hline $\begin{array}{l}\text { Diabetes (A1C) } \\
\text { BGM (mg/dl) } \\
\text { (Consider finger-stick BGM if A1C is not } \\
\text { available) }\end{array}$ & $\begin{array}{c}5.8-6.49 \text { or } \\
100-120 \mathrm{mg} / \mathrm{dl} \\
{[1]}\end{array}$ & $\begin{array}{c}6.5-8.49 \text { or } \\
120-160 \mathrm{mg} / \mathrm{dl} \\
{[2]}\end{array}$ & $\begin{array}{c}\geq 8.5 \mathrm{or} \\
>160 \mathrm{mg} / \mathrm{dl} \\
\quad[3]\end{array}$ \\
\hline Renal & $\begin{array}{c}\text { None } \\
{[0]}\end{array}$ & $\begin{array}{l}\text { Acute or chronic renal } \\
\text { insufficiency } \\
{[2]}\end{array}$ & $\begin{array}{l}\text { Chronic renal insufficiency on dialysis } \\
\text { [3] }\end{array}$ \\
\hline Hepatic & $\begin{array}{c}\text { None } \\
{[0]}\end{array}$ & $\begin{array}{l}\text { Chronic hepatitis } \\
\text { [2] }\end{array}$ & $\begin{array}{l}\text { Cirrhosis } \\
{[3]}\end{array}$ \\
\hline Immuno-compromised state & $\begin{array}{c}\text { None } \\
{[0]}\end{array}$ & $\begin{array}{c}1 \text { stable condition } \\
{[2]}\end{array}$ & $\begin{array}{c}\text { The presence of ANY: } \\
\text { Cancer (active treatment) } \\
\text { Bone marrow/organ transplantation } \\
\text { Immune deficiencies } \\
\text { Poorly controlled HIV/AIDS } \\
\text { Chronic steroid use } \\
{[3]}\end{array}$ \\
\hline
\end{tabular}

Patients who score $\leq 7$ points may be considered low risk, those scoring 8-14 points are moderate risk, and high-risk patients are those who score $\geq 15$ points.

$\mathrm{BGM}=$ blood glucose meter; $\mathrm{BMI}=$ body mass index $\mathrm{CAD}=$ coronary artery disease $\mathrm{CHF}=$ congestive heart failure; $\mathrm{COPD}=$ chronic obstructive pulmonary disease; $\mathrm{HTN}=$ hypertension 


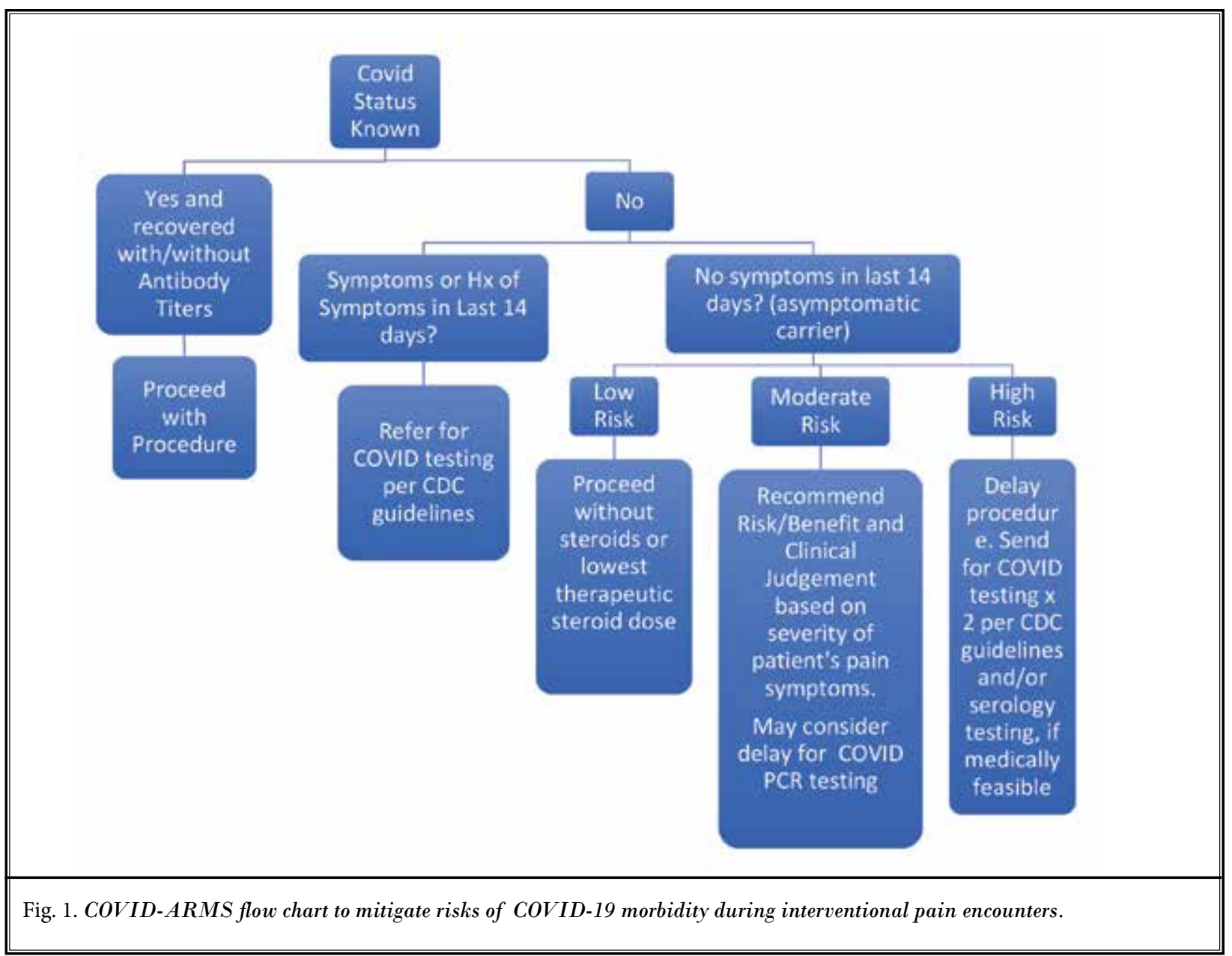

also a predictive factor for COVID-19 hospitalization, with older age associated with higher rates of hospitalization (25). Comorbidities varied with age groups as shown in Table 4. A single-center study from Wuhan China of the initial patients ( $n=41$ admitted by January 2, 2020 in China) reported $32 \%$ of these patients had comorbid conditions, of which the most frequently reported were diabetes (20\%), hypertension $(15 \%)$, and cardiovascular disease (15\%) (26). This early study from Wuhan reported $49 \%$ of the patients were between the ages of $25-49$ and $34 \%$ were between the ages of 50 and 64 (26). In a study from Korea, $90.7 \%$ of all fatalities in COVID-19 involved a patient with at least one comorbidity, the most frequently reported of which were hypertension, cardiovascular conditions, diabetes, dementia, and stroke (27).

Persons with specific underlying conditions may be at elevated risk for more severe or negative outcomes with COVID-19 than people who do not have these un- derlying conditions (28). The China Centers for Disease Control and Prevention published case fatality rates for comorbidities: hypertension $6.0 \%$, diabetes $7.3 \%$, cardiovascular disease $10.5 \%$, chronic respiratory disease $6.3 \%$, and cancer $5.6 \%$ (29).

In a study of 52 critically ill COVID-19 patients (mean age 59.7 years), 20 survived and 32 died (30). When comparing survivors to non-survivors, survivors had lower rates of comorbidities ( $20 \%$ vs. $53 \%$, respectively); the most commonly occurring comorbidities reported for survivors versus non-survivors, respectively, were: cardiovascular disease ( $20 \%$ vs. $53 \%)$, chronic cardiac disease (10\% vs. $9 \%$ ), and cerebrovascular disease ( 0 vs. $22 \%$ ) (31). In addition to comorbid disease, risk factors for COVID-19 also include age, nursing home or congregate residence, and immune-system status. While COVID-19 infects both sexes about equally, men have a higher case fatality rate than women $(3.6 \%$ vs. $1.6 \%)(32)$. 
Pain Physician: August 2020 COVID-19 Special Issue 23:S161-S182

Table 4. The most frequently reported comorbidities stratified by age range from COVID-NET in a study of hospitalized patients from March 1-28, 2020 in the United States (21).

\begin{tabular}{|c|c|c|c|}
\hline Most Frequently Reported Comorbidities & $\begin{array}{c}\text { Obesity } \\
\text { Chronic Lung Disease } \\
\text { Diabetes } \\
\end{array}$ & $\begin{array}{c}\text { Obesity } \\
\text { Hypertension } \\
\text { Diabetes } \\
\end{array}$ & $\begin{array}{c}\text { Hypertension } \\
\text { Obesity } \\
\text { Chronic Lung Disease } \\
\end{array}$ \\
\hline \multicolumn{4}{|l|}{ Specific Comorbidities } \\
\hline Hypertension & $17.5 \%$ & $47.4 \%$ & $72.6 \%$ \\
\hline Obesity & $59.0 \%$ & $49.0 \%$ & $41.0 \%$ \\
\hline Diabetes & $19.6 \%$ & $32.1 \%$ & $31.3 \%$ \\
\hline Chronic lung disease & $36.4 \%$ & $28.3 \%$ & $38.7 \%$ \\
\hline Chronic obstructive pulmonary disease & 0 & $5.7 \%$ & $22.6 \%$ \\
\hline Coronary artery disease & 0 & $12.5 \%$ & $25.4 \%$ \\
\hline Congestive heart failure & $4.7 \%$ & $5.4 \%$ & $9.5 \%$ \\
\hline Neurologic disease & $7.3 \%$ & $3.8 \%$ & $25.4 \%$ \\
\hline Immunosuppressive condition & $11.6 \%$ & $7.4 \%$ & $10.2 \%$ \\
\hline GI/Liver disease & $2.3 \%$ & $1.8 \%$ & $12.1 \%$ \\
\hline Autoimmune disease & $2.4 \%$ & 0 & $12.1 \%$ \\
\hline
\end{tabular}

\subsection{Age}

From COVID-NET, the majority of Americans hospitalized for COVID-19 (74.5\%) were $\geq 50$ years of age (25). Hospitalization rates increased with age and among individuals $\geq 85$ years, hospitalization rates were $17.2 \%$ compared to $2.5 \%$ for people between the ages of 18 and 49 (25). In a study of 1,591 COVID-19 patients from the Lombardy region in Italy, it was found that patients $\geq 64$ years had a higher mortality rate than those $\leq 63$ years ( $36 \%$ vs. $15 \%$, respectively, $95 \%$ confidence interval $[\mathrm{Cl}], 17 \%$ to $26 \%, \mathrm{P}<0.001)(33)$. In a study of 5,700 COVID-19 patients at 12 hospitals in the area in and around New York City from March 1-April 4, 2020, outcomes were assessed in 2,634 patients who were discharged or died. Of these patients, $14.2 \%$ were treated in an ICU (median age 68 years, interquartile range 56 to 78 years) and $21 \%$ died; the median age of the general population in New York City is 35.8 years (34). In a retrospective study from a single center in Wuhan, China, $49.1 \%$ of a total of 548 admitted for COVID-19 had severe disease with older age a risk factor for severe COVID; mortality for COVID-19 was $1.1 \%$ in non-severe and $32.5 \%$ in severe cases over a mean 32 days of follow-up (35).

New York City Health Department daily death summaries dated April 14, 2020 showed that patients with increasing age with or without underlying conditions had a higher risk of mortality (36). In a report of over 6,840 deaths in New York City, patients $\geq 75$ years comprised $47 \%$ of all reported deaths, while patients in the age range of 0 to 44 years made up $<5 \%$ of all deaths (Figs. 2 and 3).

By contrast, the rate of COVID infections appears low in pediatric patients and when infection does occur, it tends to be mild or asymptomatic (37). The reasons for this remain to be elucidated.

\subsection{Nursing Home or Long-Term Care Residence}

One of the earliest cases in the United States of infection in a skilled nursing facility occurred in King County, Washington, where eventually 129 cases of COVID-19 in 81 residents, 34 staff members, and 14 visitors to the nursing home could be identified, resulting in 23 deaths. The rapid spread of COVID-19 in this nursing home occurred in February 2020 and was attributable to lack of effective infection control protocols in place (38). Hospitalization rates were $54.4 \%$ for nursing home residents, $50.0 \%$ for visitors, and $6.0 \%$ for staff members (39). There are over 15,000 skilled nursing facilities in the United States, which are home to many of the country's frailest and most vulnerable citizens. Stricter and more comprehensive protection protocols have since been implemented.

The American Geriatric Society has issued guidance for nursing homes that include: ramping up infection control, not allowing visitors into the facility, and eliminating group activities within the institution $(40,41)$. PPE, including masks, face shields, gloves, and gowns, should be worn by all front-line clinicians when interact- 
ing with patients, and steps should be taken in advance to assure for the safe and rapid transfer of COVID-19 patients to local hospitals, if needed. Likewise, protocols should be in place for the safe return of such patients back to the nursing home once the COVID-19 infection has cleared. Policies and protocols for transfers and transportation to and from nursing homes may be considered with area hospitals, ambulance companies, and public health authorities (41).

\subsection{Pulmonary Disease}

Chronic lung disease was observed in about one-third $(34.6 \%)$ of those hospitalized for COVID-19 in March 2020 as reported by COVID-NET (25). In a meta-analysis ( $n=1558$ patients), chronic obstructive pulmonary disease (COPD) emerged as an independent risk factor for COVID-19 with an odds ratio of 5.97 ( $P$ $<0.001$ ) (42). There is a paucity of evidence specifically addressing smoking as a risk factor for COVID-19, although a recent review suggests that smoking is likely associated with negative progression of the infection (43). Acute Respiratory Distress Syndrome (ARDS) secondary to COVID-19 is a potentially life-threatening condition (44).

\subsection{Cardiovascular Conditions}

From COVID-NET data, $49.7 \%$ of those hospitalized

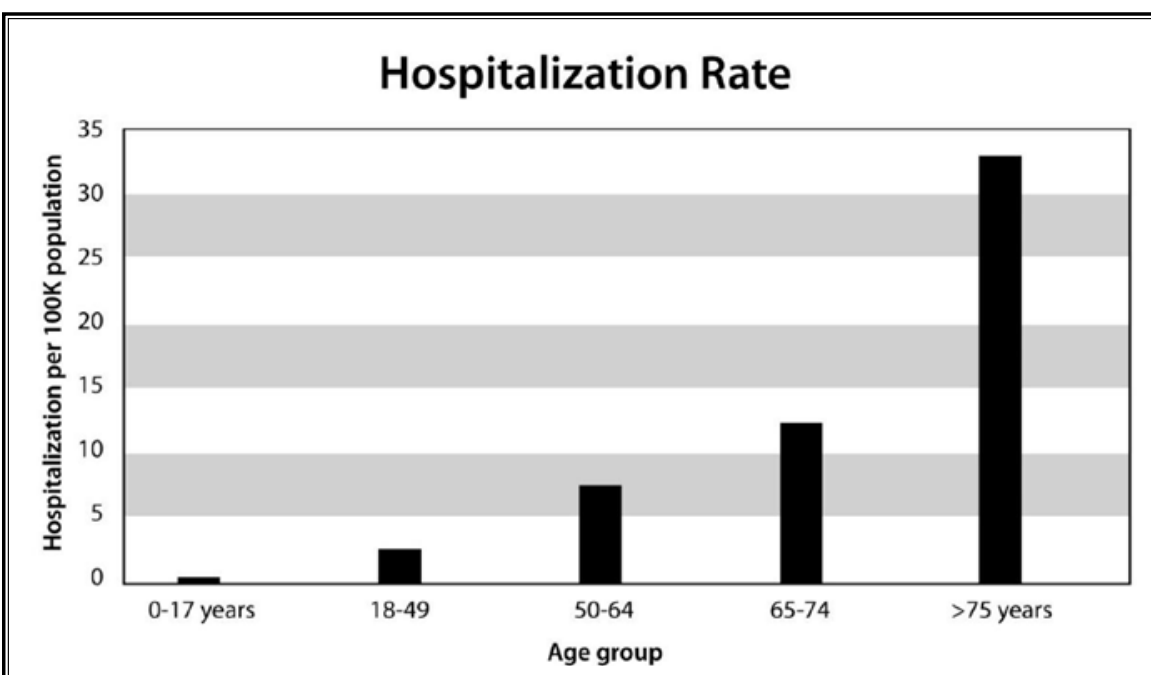

Fig. 2. The effect of age on rate of hospitalization per 100,000 population in COVID-19 disease.

Adapted from: COVID-NET, Centers for Disease Control and Prevention, 14 states, March 1-30, 2020) (51).

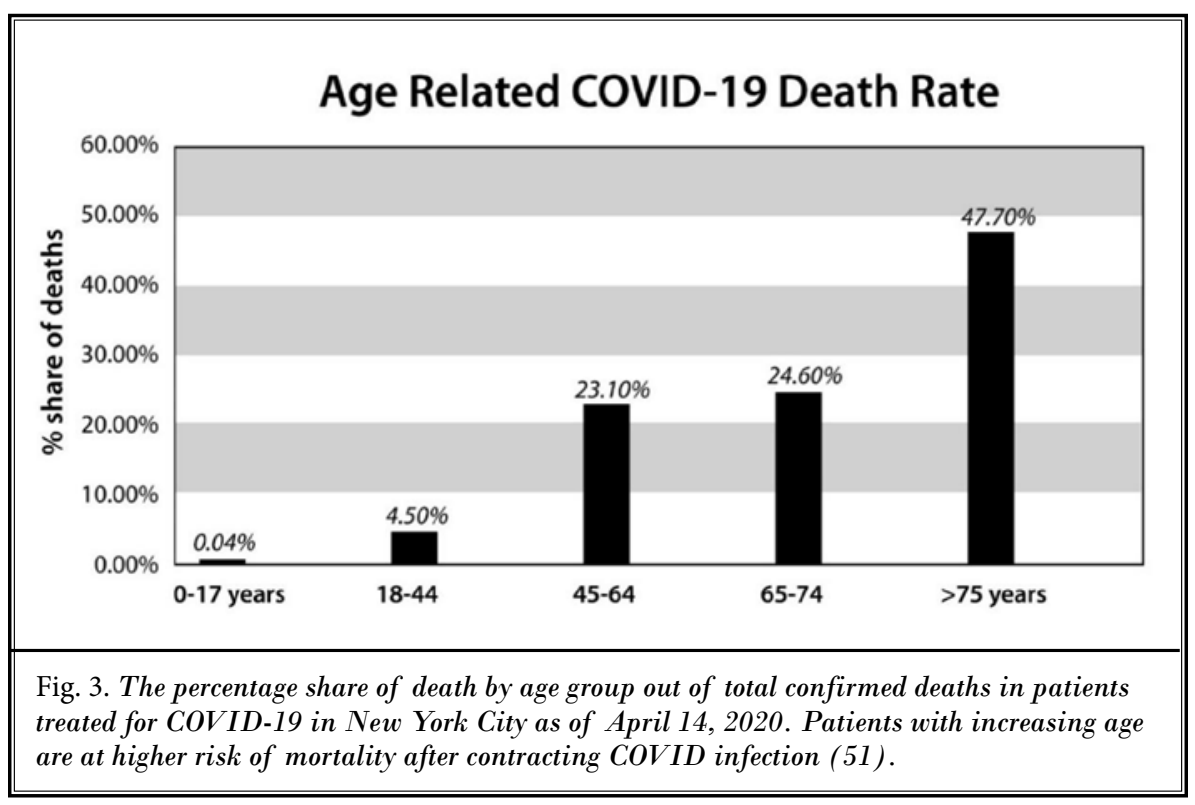

for COVID-19 in March 2020 had hypertension and 27.8\% had cardiovascular disease (25). The rate of hypertension in the general U.S. population as determined by the National Health and Nutrition Examination Survey is about 29\% (45). Indeed, hypertension was the single most frequently reported comorbidity in COVID-19 hospitalized patients in the United States and in international studies. In a metaanalysis, hypertension had an odds ratio of 2.29 for its association with COVID-19 $(P<0.001)$. 
Hypertension remains an important consideration in the overall health of all patients, particularly those with or at risk of COVID-19, but according to the American Heart Association, it is not clear whether controlled or uncontrolled high blood pressure is a risk factor for acquiring COVID-19 (46). Hypertension and other forms of cardiovascular disease are prevalent among COVID-19 patients and these conditions are often treated with angiotensin-converting enzyme (ACE) inhibitors and angiotensin receptor blockers (ARBs). Since that the presumptive entry point of the SARS$\mathrm{nCoV}-2$ virus is the ACE2 receptor, it has raised concerns as to whether or not ACE inhibitors or ARBs might be beneficial or deleterious to COVID patients or whether these drugs might affect how susceptible a person is to contracting the virus (47). This continues to be an area of active investigation without clear consensus. There is no evidence that the use of ACE inhibitors or ARBs is harmful or beneficial during the COVID-19 pandemic. It is recommended that these agents should be continued to control blood pressure and not discontinued based on current evidence (48).

Cardiovascular disease had a higher odds ratio for its association with COVID-19 at 2.93, $(P<0.001)$ and cerebrovascular disease had an odds ratio of 3.89 ( $P=$ 0.002 ) (42). Much is emerging about the cardiological sequelae of COVID-19. Autopsy findings on COVID-19 patients suggest that myocardial tissue may be infiltrated by interstitial mononuclear inflammatory cells leading to myocarditis (49). Myocarditis, in turn, may be associated with infection-related myocarditis and/or ischemia. Furthermore, COVID-19 patients with cardiac injury had a higher rate of ARDS (58.5\% vs. $14.7 \%, \mathrm{P}<$ $0.001)$ and greater mortality (51.2\% vs. $4.5 \%, P<0.001)$ than those without cardiac injury (50).

\subsection{Obesity}

Nearly half (48.3\%) of all people hospitalized for COVID-19 in March 2020 were obese according to COVID-NET data (25). While younger patients are generally seen as having a lower risk for COVID-19 compared to older patients, obesity may be an equalizing factor affecting pulmonary mechanics and oxygen consumption requirements and emerges prominently as a risk factor of particular relevance for younger patients. Since about $40 \%$ of all adults in the United States have a body mass index $(\mathrm{BMI}) \geq 30$, obesity has far-reaching implications as a risk factor for chronically obese nations, such as the United States. Furthermore, obese COVID-19 patients may find difficulties in transport and care at hospitals not equipped to manage the special needs of very large patients (51).

A retrospective study of BMI in COVID-19 patients presenting at a large academic hospital in New York City ( $n=3,615$ ) found overall $21 \%$ had a BMI 30 to 34 and $16 \%$ had a $\mathrm{BMI} \geq 35$ (52). Among patients under age 60 , those with a BMI between $30-34$ were twice as likely to be admitted to acute care $(2.0,95 \% \mathrm{Cl}, 1.6-2.6$, $\mathrm{P}<0.0001)$ and 1.8-times more like to be admitted to critical care $(1.8,95 \% \mathrm{Cl}, 1.2-2.7, \mathrm{P}=0.006)$ than individuals with a $\mathrm{BMI}<30$. Among patients under the age of 60 , those with a BMI $\geq 35$ were 2.2 and 3.6 times more likely to be admitted to acute and critical care, respectively, $(95 \% \mathrm{Cl}, 1.7-2.9$ and $2.5-5.3$, respectively, $\mathrm{P}<0.0001$ for both) compared to patients with a BMI $<30$ (52).

In a retrospective cohort study of 124 consecutive patients admitted to the ICU with diagnosed COVID-19 at a single center in France, obesity (defined as BMI > 30 ) and severe obesity (BMI >35) were present in $47.6 \%$ and $28.2 \%$ of all cases, respectively. In this population, $68.6 \%$ required invasive mechanical ventilation (IMV) and the proportion of patients who required IMV increased with larger BMI. Of patients with a $\mathrm{BMI}>35$, $85.7 \%$ required IMV. For patients with a $\mathrm{BMI}>35$, the odds ratio for IMV was 7.36 (1.63-33.14, $\mathrm{P}=0.02)$ compared to patients with a $\mathrm{BMI}<25$ (53).

\subsection{Diabetes}

COVID-NET found that $28.3 \%$ of Americans hospitalized for COVID-19 in March 2020 had diabetes mellitus (25). In a meta-analysis, diabetes had an odds ratio of 2.47 for its association with COVID-19 $(n=1,558$ patients), $P<0.001$ (42). As diabetes is comorbid with obesity, hypertension, and heart disease, it was unclear at first if diabetes was an independent risk factor for COVID-19 (54), although plasma glucose levels and diabetes have been recognized as independent risk factors for morbidity and mortality with the SARS coronavirus (SARS-CoV-1) (55). Evidence is clear that there is a higher incidence of COVID-19 in patients with diabetes (56), and the literature states that it should be considered as a risk factor for rapid progression of COVID-19 as well as poor outcome (57). Since diabetes is more prevalent in certain communities and nations, this may affect case rate distributions. It is unclear if and in what way glycemic control in diabetic patients with COVID-19 might affect the disease trajectory or outcome (58).

It should be noted that full diabetes need not be present for patients to have an elevated risk for 
infection. Postoperative hyperglycemia increases the risk of a postoperative infection and increased length of hospital stay, independent of diabetes status, in all patients undergoing general surgery. A retrospective study ( $n=995$ ) of general and vascular surgery patients found postoperative hyperglycemia increased the risk of postoperative infection by $30 \%$ for every 40 -point incremental increase over normoglycemia (< $110 \mathrm{mg} /$ dL) (59). Furthermore, hyperglycemia was found to be an independent risk factor for surgical-site infection in the first 30 days following orthopedic trauma surgery in patients with no history of diabetes (60). Note that these studies were for postoperative surgical infections and not COVID-19 and it is not clear if these results can be generalized to COVID-19.

\subsection{Renal Dysfunction}

A meta-analysis of COVID-19 patients ( $n=1,558)$ found no correlation between an elevated risk for COVID-19 and renal disease (42). However, emerging evidence suggests that kidney disease may play a role in COVID-19. Acute kidney injury (AKI) has emerged as an independent risk factor for in-hospital mortality among COVID-19 patients (61). AKI developed in 5\% to $15 \%$ of those infected with the SARS-CoV-1 and MERS-CoV, two earlier beta-coronaviruses related to the novel SARSnCoV-2 associated with COVID-19 (62). Initial reports of AKI in COVID-19 patients stated rates of 3\% to $9 \%$ but in the ensuing weeks, reports of other renal abnormalities followed (62). In a study of hospitalized COVID-19 patients ( $n=59$ ), 34\% developed massive albuminuria on the day they were admitted and $63 \%$ developed proteinuria over the course of their hospital stay (61). In $27 \%$ of COVID-19 patients, blood urea nitrogen (BUN) levels were abnormally high and BUN was elevated in twothirds of patients who died of COVID (62). The mechanism by which the SARS-nCoV2 causes kidney damage remains to be elucidated. It has been suggested that the virus causes sepsis, triggering a so-called cytokine storm, which, in turn, causes cellular injury to the kidney. It has also been pointed out that ACE2 receptors, the presumptive entry point for the SARS-nCoV-2 virus, are expressed on renal tubular cells (63). However, it must be noted that ACE2 receptors are expressed in many parts of the body and not just in the kidney system, with the greatest amount located in the lungs.

The effect of COVID-19 on patients with pre-existing chronic kidney disease has not yet been reported. Moreover, COVID-19 may complicate care for patients on dialysis, since these patients are already at elevated risk for infection $(62,64)$. Dialysis patients include the elderly, immunocompromised individuals, the frail, and patients with other comorbidities, such as hypertension. However, dialysis patients must continue with their treatments and the National Kidney Foundation has issued guidance for dialysis patients and clinicians involved in dialysis treatments (65).

\subsection{Hepatic Dysfunction}

Hepatic dysfunction has been reported in earlier beta-coronavirus epidemics (SARS and MERS), but less is known about liver dysfunction in COVID-19. Those with mild liver derangement and/or insufficiency do not seem to be at elevated risk for developing sequelae related to COVID-19 (66). A meta-analysis ( $n=1558)$ was unable to find an association between hepatic disease and elevated risk for COVID-19 (42). However, COVID-19 has been associated with acute liver injury with rates ranging from $15 \%$ to $78 \%$. COVID-19 patients may exhibit abnormal levels of alanine aminotransferase (ALT) and aspartate aminotransferase (AST) and somewhat elevated levels of bilirubin (67). However, these laboratory results may not necessarily be associated with serious clinical consequences (68). The mechanisms behind liver injury in COVID-19 patients are not known, but speculation has implicated virus-induced cytopathy and cytokine storm (67). Liver injury in some COVID-19 patients may be related to the use of hepatotoxic drugs and/or multiple organ dysfunction (69).

Based on the two largest COVID-19 studies to date, those with underlying severe hepatic disease or irreversible hepatic damage have severely worsened outcomes with COVID-19 $(66,70)$. Approximately $2 \%$ to $11 \%$ of people diagnosed with COVID-19 had a pre-existing liver condition (71), and patients with hepatitis B were more likely to have severe than non-severe COVID-19 (2.4\% vs. $0.6 \%$ ) (70). In a retrospective study of 148 consecutive COVID-19 patients a single center in China in January 2020, it was found that over one-third of those admitted to the hospital had abnormal liver function which was associated with a longer length of stay (15.09 \pm 4.79 days vs. $12.76 \pm 4.14$ days, $P=0.021)(72)$.

Clinicians cannot be complacent about the risks of COVID-19 in patients with chronic liver disease and cirrhosis, because these patients have poor immune function and worse outcomes from acute respiratory distress syndrome than other critically ill patients (66).

\subsection{Immunocompromise}

Immunocompromised patients have limited ability 
to fight infection and this population includes many subpopulations: people with certain immunosuppressive diseases (such as diabetes or AIDS), those taking certain drugs or undergoing therapies that suppress the immune system (chemotherapy, organ transplant patients), and those who are genetically immunodeficient. While transplant patients $(73,74)$ and cancer patients undergoing radiation and/or chemotherapy $(75,76)$ appear to be at elevated risk for contracting COVID-19, HIV patients may not be at increased risk for COVID-19 (77). It is theorized that the widespread use of antiretroviral therapy in HIV patients has restored immune function; if this theory is true, HIV patients who do not take antiretroviral drugs may not benefit from this protection against COVID-19 (78). The risks of immunocompromised patients are still being elaborated; for example, a study and review from Italy concluded that immunosuppressed patients are not at a higher risk for severe pulmonary disease compared to non-immunosuppressed patients in the general population (79).

Cancer patients should be instructed to strictly observe hand hygiene, social distancing, and other protocols but delaying adjuvant chemotherapy or other procedures related to cancer must be evaluated on a case-by-case basis in cancer patients at low risk for rapid disease progression (80). Although there are no robust data, patients with lung cancer may be at particular risk with COVID-19 (80).

\subsection{Coagulation Abnormalities in COVID-19 INFECTION}

Coagulation abnormalities are prevalent in patients with severe infection. It remains to be elucidated whether these coagulation disorders are related to viral factors or if they are secondary to systemic inflammation relating to cytokine release ("cytokine storm"). According to the American Society of Hematology, the most common pattern of coagulopathy observed in patients hospitalized with COVID-19 is characterized by elevated fibrinogen and D-dimer levels, which, in turn, correlate to an increase in inflammation markers (81). It is thought that this represents a prothrombotic state, even without evidence of microangiopathy or a hemorrhagic diathesis.

Patients with severe COVID-19 may develop a coagulopathy meeting criteria for disseminated intravascular coagulation (DIC) according to the International Society on Thrombosis and Haemostasis (ISTH) (82). This is reflected by moderate to severe thrombocytopenia (platelet count $<50 \times 109 / \mathrm{L}$ ), prolongation of the PT and aPTT, marked elevation of D-dimer and decreased fibrinogen $(<1.0 \mathrm{~g} / \mathrm{L})$. The development of DIC occurred in $71 \%$ of those dying in a cohort of 183 hospitalized COVID-19 patients; deceased patients had higher serum D-dimer and fibrinogen degradation product levels than those who recovered (83).

\subsection{Testing Guidelines}

There are two main types of tests for COVID-19, a viral test to ascertain whether a person has a current infection and an antibody test to see if one has experienced a prior infection. The CDC has assigned priorities for testing people. Based on this guidance dated May 3, 2020, Table 5 shows these testing priorities (84). According to the CDC, people with suspected COVID-19 should contact their healthcare provider by telephone first to determine if testing is warranted and available. For

Table 5. COVID-19 testing prioritization based on CDC guidance (patients with priority or high priority testing needs).

\begin{tabular}{|c|c|c|}
\hline POPULATION & "TESTING PRIORITY & COMMENT \\
\hline \multicolumn{3}{|c|}{ With Symptoms } \\
\hline Hospitalized patients & High priority & \\
\hline Healthcare workers and first responders & High priority & $\begin{array}{l}\text { Particularly those who work in or with nursing homes, } \\
\text { prisons or other group living facilities }\end{array}$ \\
\hline $\begin{array}{l}\text { Residents in congregate living centers such as } \\
\text { nursing homes or prisons }\end{array}$ & High priority & The living conditions make rapid disease spread possible \\
\hline Individuals & Priority & $\begin{array}{l}\text { Symptoms are: fever, cough, dyspnea, chills, muscle pain, } \\
\text { new loss of taste or smell, vomiting, diarrhea, sore throat }\end{array}$ \\
\hline \multicolumn{3}{|c|}{ Without Symptoms } \\
\hline $\begin{array}{l}\text { Individuals who have been identified by health } \\
\text { departments or clinicians as being at risk }\end{array}$ & Priority & $\begin{array}{l}\text { Testing may be important for public health monitoring, } \\
\text { sentinel surveillance, or screening of asymptomatic } \\
\text { individuals according to state or local health plans }\end{array}$ \\
\hline
\end{tabular}


many people with mild symptoms, testing may not be necessary and recovery can take place at home without specialized medical care.

The CDC has also prioritized testing for individuals with symptoms of COVID-19 who are considered at risk for poor outcomes, people who have had close contact with a confirmed or suspected COVID-19 patient in the past 14 days, and those who have recently traveled to a COVID-19 "hot spot" (85). In general, the CDC does not recommend testing asymptomatic individuals except in special situations (85). In addition to these CDC guidelines, state and local health authorities may have specific recommendations. While a variety of testing options are available and testing is becoming increasingly accessible, there still remain gaps in terms of evaluating asymptomatic patients, infected people in the incubation period, and recovered patients who may still be shedding the virus (85).

Clinicians must use their judgment as to whether a patient with signs and symptoms of COVID-19 should be tested. Prioritized testing may be appropriate for the entire population residing in long-term care, nursing homes, or other group living situations; testing minimally symptomatic or even asymptomatic people may help to avoid an outbreak. This becomes particularly important when one or more other residents in a given group-living facility have been diagnosed with COVID-19.

Diagnosis is challenging because people with COVID-19 infections may be asymptomatic, pre-symptomatic, or minimally symptomatic; viral shedding may occur by people unaware they are infected, potentially infecting others (86). For this reason, potentially exposed healthcare personnel or others with close and extensive contact with vulnerable people in clinical or residential care settings should be evaluated even when they have only mild signs and symptoms of COVID-19. This may also apply to patients undergoing surgery. In a retrospective study of 34 patients undergoing elective surgery during the incubation period of what was later confirmed to be COVID-19, all developed pneumonia after surgery with abnormal findings on chest computed tomography scans. In this study, $44 \%$ of patients required ICU hospitalization and had a mortality rate of $20 \%$ (87).

\subsection{Laboratory Methodology for COVID-19 PCR ANd Serology Testing}

The two available tests for COVID-19 are polymerase chain reaction (PCR) test or a blood-based serol- ogy test. The PCR test assesses the presence of the virus in the respiratory tract, using either a nasopharyngeal or oropharyngeal swab, sputum, or bronchoalveolar lavage fluid. PCR tests detect the presence of specific parts of the viral RNA genome in the respiratory secretions. The PCR test kits from the CDC test for two regions of the viral neucleocapsid gene (N1 and N2), while the WHO offers a test that targets the SARSnCoV-2 RNA-dependent RNA polymerase (RdRP) and envelope genes. Both tests have high sensitivity and specificity for SARS-nCoV-2 with minimal cross-reactivity with other circulating strains of coronaviruses (85).

The serological tests are designed to detect the presence of COVID-specific IgM, IgG, and IgA antibodies in the blood/serum or saliva. These antibodies can be detected during the convalescence period, which is usually seven to 19 days following the onset of symptoms; these antibodies would also be detectable following vaccine, which is in development. These antibodies are thought to be surrogate markers for infection immunity, although this is not definitely proven (88). The IgM test is nonspecific and is not recommended to assess immunity; it is not useful for diagnosing acute infection but may indicate evidence of a past infection or vaccination. Caution is urged as their diagnostic accuracy and clinical utility are as yet undefined and unproven and are primarily being used for epidemiologic purposes.

As patients with chronic pain return for care, universal COVID-19 serology with or without PCR testing may be necessary prior to having the patient undergo any intervention or other procedure. Risk assessment should be performed prior to patient contact. This may involve a telephonic interview, at which point it may be appropriate to inquire about the patient's history of COVID-19 infection, recent travel, history of possible contact with infected people in their community, the presence of absence of symptoms such as cough and fever, assessment of body temperature and, if available, testing for COVID-19. While desirable, testing options may not always be available or feasible for all patients in all locations. Patients should be evaluated, stratified for risk, and tested when indicated. Patients for whom risk exceeds benefit should have their procedure delayed until they can be optimized. Medical consultations and clearance may be considered in such individuals. If an interventional pain management is indicated in a high-risk individual, consideration should be given to avoiding steroids or using the lowest effective dose (Fig. 1). 


\subsection{Clinical Practice Management}

The COVID-19 era has affected the lives of patients and practices in immeasurable ways. Much of the historical ways of practicing medicine based on past experiences and individual mindsets are coming under scrutiny and they are currently being re-analyzed, adjusted, and adapted to a new plane of practice that seeks to reduce patient risk while optimizing benefits. In caring for patients, there are three questions to ask to better individualize care to meet individual needs.

1. What is the level of risk for COVID-related morbidity and mortality (the COVID-ARMS score can be used)? (Table 3).

2. If the patient requires a steroid injection, is there evidence to support that steroids will benefit the patient's condition?

3. What is the lowest effective dose of steroid that can be administered to the patient to achieve a successful outcome?

The COVID-ARMS scoring system was designed to assist clinicians in developing plans of care for optimal outcomes for individual patients. It may be seen as a risk-mitigation tool, where the greater the score, the greater the number of precautions that may be required to reduce the risk of harm. Of course, pain medicine is not a mathematical system and this scoring metric is not meant to supersede clinical judgment, evolving knowledge, and the patient's condition. Rather, the COVID-ARMS score should serve as a tool for pain physicians and be part of a larger mosaic of considerations in the medical decision-making process. It is not intended to override sound clinical judgment for an individual patient's unique needs.

Patients with low-risk COVID-ARMS scores ( $\leq 7)$ may be managed using standard precautions for infection prevention that protects the patient, clinicians, and staff. The lack of widespread testing and the possibility for asymptomatic and low-risk patients to transmit the disease combined with the inherently unpredictable nature of interventional pain procedures deserves special consideration. Even in seemingly low-risk patients with routine procedures, care must be taken particularly for procedures involving the head or neck area or those that involve having the patient lie in a supine position. Standard precautions are required but should be supplemented with N95-type protective masks, eye protection, and a surgical gown for the physician performing the procedure and anyone else within six feet of the patient. Masks and eye protection are recommended for everyone in the room. When indicated, steroids may be used but should be administered at the lowest possible effective dose. Although injected steroids may alter immunity, this patient population is considered sufficiently healthy and at lowest risk for interventional pain medicine.

Moderate and high-risk patients on the COVIDARMS scale may be viewed on a continuum where a range of measures to maximize patient benefit and reduce harm can be progressively introduced to improve outcomes, up to and including performing a less-risky interventional procedure or not performing it at all, given the risk to the individual. At this time, there are no interventional risk reduction strategies specifically based on COVID-19. However, it can safely be stated that the systemic and immunosuppressive effects of injected steroids at the lowest effective dose would be considerably less than a three-to-five-day course of oral steroids.

There is no evidence that short-acting versus longacting steroids improve COVID-19 outcomes. It would be imprudent to expose the patient to the technical and infectious risk of a procedure using an unproven steroid that may not produce therapeutic benefits, for example, dexamethasone in an intra-articular space. In this population of patients at moderate to high risk based on the COVID-ARMS score, procedural and injectate decisions need to be carefully weighed. For high-risk patients, consideration should be given to the patient's clinical presentation and diagnoses in order to determine if steroids should be used at all and whether the procedural risk is warranted. After evaluating the risks and benefits of various techniques and injectates, it may also be worth considering performing the procedure in high-risk patients without steroids or with a reduced dose of steroids.

\subsection{Steroids and Steroid-Related Immune Suppression}

Corticosteroid-related immunosuppression was first demonstrated in an animal model of allograft rejection in the 1950s (89). Although corticosteroidrelated immunosuppression has not been a significant consideration in interventional pain medicine prior to the COVID-19 era, concerns about the effects of injectable steroids on the immune system are being actively discussed in the interventional pain medicine community (90). Furthermore, corticosteroids exert a variety of effects that may be either beneficial or deleterious to optimal outcomes in interventional pain medicine. There are many dose-related adverse effects of cor- 
ticosteroids, ranging from osteoporosis and related consequences, such as vertebral compression fractures, avascular necrosis, inhibited wound healing, easy bruisability, adipose tissue redistribution leading to the infamous "buffalo hump," painful myopathy, diabetes, and neuropsychiatric changes, among many others.

The immunological effects relevant to COVID include elevated glucose levels that predispose an individual to an infection, migratory inhibition of leukocytes, inhibition of production of inflammatory mediators such as interleukins and macrophage migration inhibition factor (MIF), to inducing sequestration of CD4+ T-lymphocytes in the reticuloendothelial system (RES) and inhibitory effects on proliferation and function of lymphocytes via inhibition of lymphokines and cytokines (91).

Interventional pain clinicians administer a wide range of single and combination agents into various parts of the body ranging from soft tissue, joint spaces and peripheral nerves to spinal structures. The injectates are single or multiple agents that may include saline, local anesthetics, steroids, clonidine, opioids, ketamine, Sarapin, and others. When steroids are more frequently utilized, such as during the performance of therapeutic intra-articular or epidural steroid injections, physicians tend to have a preferred agent(s) and dose(s) (92). These vary among clinicians and may not always be based on rigorous assessment or evidence. The general state of the literature is that steroids are, at best overutilized and unnecessary; at worst, they are potentially harmful agents without proven benefit (92).

Although many peripheral and spinal injections use an admixture of steroids with saline or local anesthetics, there may be cases in which steroids are not indicated, such as during the performance of trigger point injections, purely diagnostic peripheral or central nerve block, and epidural "steroid" injections that can instead be performed with local anesthetic and saline with similar outcomes. For instance, interventional pain specialists utilize epidural steroids for a wide spectrum of clinical indications ranging from an acute lumbar radiculopathy secondary to a herniated disc to discogenic pain, failed back surgery syndrome, and neurogenic claudication secondary to degenerative spinal stenosis, although only acute lumbar radiculopathy has been shown to benefit from the introduction of steroids (92).

Even though epidurals have become very popular since 1952, local anesthetics were used prior to steroid injections in the epidural space from 1901. Multiple
RCTs and systematic reviews have shown similar effectiveness of local anesthetics alone, or local anesthetic with steroids (92).

Given the equivocal evidence for steroids in many interventional techniques together with the current lack of effective therapeutic defenses against COVID-19, clinicians should carefully consider their use at this time, in particular, their use at high doses and for patients at high risk. Even in cases where there is strong reason to suspect an inflammatory component is driving the patient's pain and steroids are indicated, a lower-than-normal dose may be considered.

While steroid use was shown to increase the risk of influenza (93), there are no similar studies regarding COVID-19. It had been speculated that steroids might have a beneficial effect on the course of COVID-19 although steroids can be immunosuppressive. In a retrospective study of patients infected in Guangzhou, China, with the older SARS virus, the use of corticosteroids was associated with lower mortality and shorter hospital lengths of stay among critical patients (94). In this study, critical patients were treated with a mean daily dose of corticosteroids of $133.5 \pm 102.3 \mathrm{mg}$ and noncritical patients received a mean daily dose of 105.3 $\pm 86.1 \mathrm{mg}$. While SARS-CoV-1 and SARS-nCoV-2 are related viruses, it is unclear if these results with an earlier coronavirus can be generalized to COVID-19 patients. A case study in the literature reported on a familial cluster of COVID-19 patients in China taking long-term steroid therapy; COVID-19 was diagnosed in three family members but had atypically long incubation periods, exceeding the usual 14-day quarantine recommendation (95). The median incubation period for COVID-19 is 5.1 days (95\% confidence interval, 4.5 to 5.8 days) and $<3 \%$ develop symptoms after 11.5 days; the recommended quarantine period is 14 days (96). The use of steroids was associated with atypical disease presentation but not worse outcome.

\subsection{Informed Consent}

As interventional pain practices re-open, there is an ethical imperative to inform patients of the risks and benefits of pain treatment in the era of COVID-19. An informed consent form may be helpful which sets forth the risks and benefits of treatment in the context of COVID-19 in plain, patient-friendly language. An informed consent form (Appendix Table 1) improves documentation, educates, outlines the key talking points that should be discussed and understood by the patient, and reduces the risk that an important area of 
concern is left out of the consent process. In this regard, it provides the patient with a document that can be reviewed at home or shown to family and caregivers.

It is important for clinicians to pay close attention to the local and state regulations. The local or state department of health and/or board of medical licensure may offer guidance and direction for appropriate protocols for the return to practice. Clinicians may set up their own protocols to screen potential patients and to operate their offices. Patients may be required to have their temperature taken, asked questions about recent exposure to an infected person, recent travels, and current symptoms. Clinical staff may be encouraged to wash hands frequently with hand-washing stations and sanitizers readily available, and cautioned about maintaining social distance. Should a confirmed case of exposure be identified, even as a patient who was only briefly at the office, contact tracing may be helpful to prevent further spread of the disease. If the clinician or clinical team comes in close contact with an infected person, self-isolation may be considered in order to prevent transmission of the virus; the self-quarantine is recommended for 14 days or until a negative COVID-19 test result can be confirmed.

\subsection{Clinical Precautions}

As interventional pain practices reopen, it is crucial that adequate PPE is provided for all staff members. PPE for healthcare professionals performing or participating in interventional pain procedures includes a hat, mask, sterile gloves, and, for more invasive procedures, a sterile gown. Some clinicians may also wish to wear a face guard, goggles, or face shield. Despite precautions, hospitals have been a very high infection site for COVID-19 spread, and it is likely that offices and ambulatory settings that are newly opening will also be sites of concern related to further COVID-19 spread.

Healthcare workers are at particularly elevated risk for infection. The CDC reports from data on U.S. cases of COVID-19 from February 12 through April 9, 2020 (n $=315,531$ cases) and states that $19 \%$ of cases involved healthcare professionals ( $n=9,282$ ) and $8 \%$ to $10 \%$ of this group required hospitalization with a mortality of $0.3 \%$ to $0.6 \%$. In the case of healthcare professionals, $37 \%$ of deaths occurred in clinicians $\geq 65$ years although they composed only $6 \%$ of the healthcare workers who contracted COVID-19 (97).

The office waiting room may have to be rearranged to accommodate the need for social distancing. As long as authorities are suggesting that people in public wear face masks, it is reasonable to consider asking that patients wear masks while at the office. Note that at the time of publication, some states and municipalities require people patronizing businesses to wear masks, and it may be required by law that clinicians provide masks for their patients and staff. Staff members should be encouraged to wash their hands often and hand sanitizer should be readily available for both staff and patients. It may be advisable to check temperatures of people entering the waiting room and those who visit the office should be asked if they have had symptoms, traveled to any COVID-19 "hot spots," or if they have had contact with a person they known COVID-19 infection. To allow for social distancing and safe practice, it is advisable to limit the number of people in the waiting rooms to patients and possibly one other person, such as a spouse or an aide.

The administrative area may also need to be reorganized to allow staff to work at least six feet apart from others, as much as possible. The use of masks should be encouraged. A protocol whereby employees are checked each morning for symptoms and have their temperatures taken is encouraged. A protocol should be put in place and staff reminded to wipe down communal surfaces with disinfectant throughout the day and to carefully clean reusable equipment between patients. This includes items like blood pressure cuffs and pulse oximeters.

During times of surge (Phase 1), strict adherence to all recommended precautions is advised. Virtual visits for existing and new patients may play an important role in how pain specialists evaluate and treat patients who do not need to come to the office in person or who may be have diagnosed or suspected COVID-19. State regulations may determine which types of procedures can be performed and they should be regarded as the primary authority. If elective procedures are permitted, the risk stratification proposed in this article should be used.

\subsection{Elective Procedural Considerations}

Many interventional pain procedures require that the patient be sedated, but sedation may increase the risk of spreading the infection. Sedated patients would not be able to wear any sort of PPE around their mouth or nose, since access to the airway is needed during the procedure. Sedated patients may produce excess secretions which can spread the virus; furthermore, they may need airway support that could require oxygen masks or tubing which may 
become contaminated with secretions. As such, it is recommended that procedures normally performed without sedation be performed without sedation or be postponed, if possible, until the patient is at low risk of spreading the disease. A checklist has been prepared by ASIPP and the Society of Interventional Pain Management Surgery Centers (SIPMS) to help clinicians return to practice at ambulatory surgery centers (Appendix Table 2). If surgical procedures with sedation must take place, sedation should be at the lowest effective level. If sedation takes place, all healthcare professionals present during the procedure are advised to wear face shields as part of their PPE and the room be thoroughly cleaned following the procedure. If the patient has a confirmed negative test or has confirmed complete recovery from COVID-19, these considerations about avoiding sedation may be relaxed based on the individual patient and the clinical situation.

There is a paucity of evidence regarding the effect of single injections of steroids utilized in pain management procedures and the concomitant risk of acquiring or exacerbating COVID-19. Anecdotal evidence and our general understanding of high-dose steroids suggest that these may have an adverse effect on patients predisposed to life-threatening infections with COVID-19. In some cases, it may be appropriate to use a single injection of a steroid, but the lowest effective dose should be used and, in some cases, it may be better to avoid steroids altogether. If steroids are considered, it may be advisable to discuss with the patient the risks and benefits.

\subsection{Managing Exposures}

Overt exposure to COVID-19 at the clinic may likely occur, for example, a patient may find out after a clinic visit that he or she had the infection or a staff member may have had personal contact with an infected individual. In such cases, rigorous adherence to recommended practices (using PPE, washing hands frequently, disinfecting equipment and contact surfaces) should confer protection. However, the clinic staff should be informed of this exposure and closely monitored for the occurrence of symptoms. If any member of the clinic staff develops symptoms suggestive of COVID-19, he or she should be isolated at once and testing sought. In the event that COVID-19 is confirmed or cannot be definitively ruled out (for instance, testing was not available), the individual should be isolated for at least two weeks after all symptoms have resolved. In the event a staff member knows someone with COVID-19, the staff member should be encouraged (if possible) to socially isolate from the infected person and observe strict social distancing from others in the workplace, while being closely monitored every day for symptoms. It should be noted that early symptoms of COVID-19 may be mild, such as fatigue, dry cough, or slightly elevated temperature. If symptoms develop, a healthcare provider should be contacted for possible testing.

\subsection{Discussion}

As the healthcare system returns to practice in phase I of the COVID-19 pandemic, the focus must be on opening up healthcare services in a strategic way, using the evidence-informed methodologies in these and other relevant, reputable guidelines. Risk stratification based on patient comorbidities must be carried out to achieve optimal outcomes. Physician discretion is crucial in order to achieve a realistic risk-benefit analysis and enter into shared decision-making with the patient. Obviously, the COVID-19 situation is fluid and changeable. Fortunately, new studies and evidence appear in the literature on a daily basis to help better guide healthcare providers.

As healthcare providers, it is important that we recognize that our patients, for the most part, are confused, distressed, and may even be angry, particularly if they are need some sort of elective surgery or procedure. Healthcare providers must recognize and appreciate these concerns. For that reason, an Informed Consent is recommended both to provide a good outline of key points in the risk assessment, to provide patients with take-home material to review at their leisure, and to serve clinical documentation. To a large extent, evidence and information dispels confusion and reduces fear; we must be generous with realistic, honest communication to our patients during this difficult time. Although healthcare providers are sometimes reticent to admit this, it is imperative at this time that we tell patients that there is much about the COVID-19 virus is unknown. Despite tremendous progress in terms of sequencing the SARS-nCoV-2 virus genome, conducting studies, identifying at-risk patient populations, and developing testing, COVID-19 seems to be an unusual and at times unpredictable disease. That being said, it is important to reassure patients that risk stratification is a sound approach and that risk mitigation strategies can be highly effective.

The COVID-19 pandemic has presented unusual challenges that may forever change the healthcare 
system. Unlike many other non-essential businesses, the work of pain care cannot simply be shut down for weeks. Chronic pain patients depend on interventional procedures to ease their suffering, promote better function, and improve their quality of life. During this time of pandemic and social uncertainty when even otherwise healthy people feel anxiety, a sense of loss, and depression, chronic pain patients may be particularly hard hit by psychological distress. For that reason, interventional pain specialists must be at the vanguard as America re-opens and clinical services resume. Our patients depend on us for their quality of life. During this most challenging time, pain physicians must be supportive, but also cautious. We must be encouraging, but realistic. We must be truthful, even when we do not have all the answers. Communication and sound science are our best weapons in the armamentarium against COVID-19. By stratifying patients for risk, testing appropriate patients, delaying procedures when appropriate, and dealing with each patient on an individualized basis, quality care can be effectively and safely resume.

There are multiple limitations to the present guidelines. The recommendations were made during the time when COVID-19 was a pandemic. At the same time, elective surgeries were stopped. The pandemic has created a situation with lack of time and literature to provide truly evidence-informed guidance. The guidance will be appended and new recommendations provided as literature continues to emerge.

\subsection{Conclusion}

As America begins the long, slow work of "reopening" the country, interventional pain specialists will be faced with unique challenges to safely and effectively treat chronic pain patients. By using the algorithms developed here to identify and stratify patients for risk, treating those who can be safely treated as soon as possible, and delaying treatment where appropriate, chronic pain patients can get the care they need without exposing themselves or those around them to unnecessary risks. Knowing the risk factors for COVID-19 and observing precautions can help reduce risk without compromising care.

\section{Author Contributions}

The concept was developed and the study was designed by the ASIPP Task Force at the request of ASIPP Board of Directors. All authors contributed to preparation to the manuscript, reviewed, and approved the content with final version.

\section{Acknowledgments}

The authors acknowledge the assistance of Jo Ann LeQuang of Angleton, Texas, who assisted with preparation of the manuscript with the consent and direction of the authors. Thanks also to Bert Fellows, MA, Director Emeritus of Psychological Services at Pain Management Centers of America, for manuscript review, and Tonie M. Hatton and Diane E. Neihoff, transcriptionists, for their assistance in preparation of this manuscript

\section{REFERENCES}

1. Centers for Disease Control and Prevention, Office of the White House. Guidelines: Opening Up America Again. https://www.whitehouse.gov/ openingamerica Accessed 6/1/2020

2. Dahlhamer J, Lucas J, Zelaya C, et al. Prevalence of chronic pain and highimpact chronic pain among adults - United States, 2016. MMWR Morb Mortal Wkly Rep 2018; 67:1001-1006.

3. Dieleman JL, Cao J, Chapin A, et al. US health care spending by payer and health condition, 1996-2016. JAMA 2020; 323:863-884.

4. Manchikanti L, Kaye $A D$, Soin $A$, et al. Comprehensive evidence-based guidelines for facet joint interventions in the management of chronic spinal pain: American Society of Interventional Pain Physicians (ASIPP) guidelines. Pain Physician 2020; 23:S1-S127.

5. Navani A, Manchikanti L, Albers SL, et al. Responsible, safe, and effective use of biologics in the management of low back pain: American Society of Interventional Pain Physicians (ASIPP) guidelines. Pain Physician 2019; 22:S1-S74.

6. Kaye AD, Manchikanti L, Novitch $M B$, et al. Responsible, safe, and effective use of antithrombotics and anticoagulants in patients undergoing interventional techniques: American
Society of Interventional Pain Physicians (ASIPP) guidelines. Pain Physician 2019; 22:S75-S128.

7. O'Connor CM, Anoushiravani AA, DiCaprio MR, Healy WL, lorio R. Economic recovery after the COVID-19 pandemic: Resuming elective orthopedic surgery and total joint arthroplasty. J Arthroplasty 2020; 35: $\mathrm{S}_{32}-\mathrm{S}_{3} 6$.

8. Mouton C, Hirschmann MT, Ollivier M, Seil R, Menetrey J. COVID-19 - ESSKA guidelines and recommendations for resuming elective surgery. J Exp Orthop 2020; 7:28.

9. Shanthanna $\mathrm{H}$, Strand $\mathrm{NH}$, Provenzano $\mathrm{DA}$, et al. Caring for patients with 
pain during the COVID-19 pandemic: consensus recommendations from an international expert panel. Anaesthesia 2020; 75:935-944.

10. Manchikanti L, Sanapati MR, Pampati V, Boswell MV, Kaye AD, Hirsch JA. Update on reversal and decline of growth of utilization of interventional techniques in managing chronic pain in the Medicare population from 2000 to 2018. Pain Physician 2019; 22:521-536.

11. Manchikanti L, Sanapati J, Benyamin RM, Atluri S, Kaye AD, Hirsch JA. Reframing the prevention strategies of the opioid crisis: Focusing on prescription opioids, fentanyl, and heroin epidemic. Pain Physician 2018; 21:309-326.

12. Wilson $N$, Kariisa $M$, Seth $P$, Smith $H$ $4^{\text {th, Davis NL. Drug and opioid-involved }}$ overdose deaths - United States, 20172018. MMWR Morb Mortal Wkly Rep 2020; 69:290-297.

13. IQVIA Institute for Human Data Science Study. Medicine use and spending in the U.S. A review of 2018 and outlook for 2023. May 2019.

https://www.iqvia.com/insights/theiqvia-institute/reports/medicine-useand-spending-in-the-us-a-review-of2018-and-outlook-to-2023 Accessed 5/28/2020

14. NIDA. Overdose Death Rates. National Institute on Drug Abuse website. January 29, 2019.

https://www.drugabuse.gov/relatedtopics/trends-statistics/overdose-deathrates Accessed 5/28/2020

15. Cortiula F, Pettke A, Bartoletti M, Puglisi F, Helleday T. Managing COVID-19 in the oncology clinic and avoiding the distraction effect. Ann Oncol2020; 31:553-555.

16. Jha SS, Shah S, Calderon MD, Soin A, Manchikanti L. The effect of COVID-19 on interventional pain management practices: A physician burnout survey. Pain Physician 2020; 23:S271-S282.

17. Graham R, Mancher M, Wolman DM, Greenfield S, Steinberg E (eds); Committee on Standards for Developing Trustworthy Clinical Practice Guidelines; Institute of Medicine. Clinical Practice Guidelines We Can Trust. The National Academies Press, Washington, DC, 2011.

18. National Guideline Clearinghouse Extent Adherence to Trustworthy Standards (NEATS) instrument.

www.ncbi.nlm.nih.gov/pubmedhealth/
PMHoo79458/ Accessed 5/28/2020

19. Harris RP, Helfand M, Woolf $\mathrm{SH}$, et al; Methods Work Group, Third US Preventive Services Task Force. Current methods of the US Preventive Services Task Force. Am J Prevent Med 2001; 20:21-35.

20. Manchikanti L, Falco FJE, Benyamin RM, Kaye AD, Boswell MV, Hirsch JA. A modified approach to grading of evidence. Pain Physician 2014; 17:E319-E325.

21. Woodbury MG, Kuhnke JL. Evidencebased practice vs. evidence-informed practice: What's the difference? Wound Care Canada, 2014; 12:26-29.

22. Tickle-Degnen L, Bedell G. Heterarchy and hierarchy: A critical appraisal of the "levels of evidence" as a tool for decision making. Am J Occup Ther 2003; 75:234-237.

23. Miles A, Loughlin M. Models in the balance. Evidence-based medicine versus evidence-informed individualized care. J Eval Clin Pract 2011; 17:531-536.

24. World Health Organization, EvidenceInformed Policy Network. EVIPNet in action: 10 years, 10 stories.

www.who.int/evidence/en/ Accessed 6/29/2020

25. Garg S, Kim L, Whitaker $M$, et al. Hospitalization rates and characteristics of patients hospitalized with laboratoryconfirmed coronavirus disease 2019 - COVID-NET, 14 States, March 1-30, 2020. MMWR Morb Mortal Wkly Rep 2020; 69:458-464.

26. Huang C, Wang Y, Li X, Ren L, Zhao J, Hu $Y$. Clinical features of patients infected with 2019 novel coronavirus in Wuhan, China. Lancet 2020; 395:497-506.

27. Korean Society of Infectious Diseases and Korea Centers for Disease C ontrol and Prevention. Analysis on 54 Mortality Cases of Coronavirus Disease 2019 in the Republic of Korea from January 19 to March 10, 2020. J Korean Med Sci 2020; 35(12):e132.

28. Centers for Disease Control and Prevention Covid-19 Response Team. Preliminary estimates of the prevalence of selected underlying health conditions among patients with coronavirus disease 2019 - United States, February 12-March 28, 2020. MMWR Morb Mortal Wkly Rep 2020; 69:382-386.

29. Zhang Y. Vital surveillances: The epidemiological characteristics of an outbreak of 2019 novel coronavirus diseases (COVID-19) -- China 2020.
China CDC Weekly 2020; 2:113-122.

http://weekly.chinacdc.cn/en/article/id/ e53946e2-c6c4-41e9-9agb-fea8dbia8f51 Accessed 5/28/2020

30. Yang Y, Peng F, Wang R, et al. The deadly coronaviruses: The 2003 SARS pandemic and the 2020 novel coronavirus epidemic in China. J Autoimmun 2020; 109::102434.

31. Yang X, Yu Y, Xu J, et al. Clinical course and outcomes of critically ill patients with SARS-CoV-2 pneumonia in Wuhan, China: A single-centered, retrospective, observational study. Lancet Respir Med 2020; 8:475-481.

32. Madjid M, Safavi-Naeini P, Solomon SD, Vardeny O. Potential effects of coronaviruses on the cardiovascular system: A review. JAMA Cardiol 2020; 5:831-840.

33. Grasselli G, Zangrillo A, Zanella A, et al. Baseline characteristics and outcomes of 1591 patients infected with SARSCoV-2 admitted to ICUs of the Lombardy Region, Italy. JAMA 2020; 323:1574-1581.

34. Richardson S, Hirsch JS, Narasimhan $M$, et al. Presenting characteristics, comorbidities, and outcomes among 5700 patients hospitalized with COVID-19 in the New York City area. JAMA 2020; 323:2052-2059.

35. Li X, Xu S, Yu M, et al. Risk factors for severity and mortality in adult COVID-19 inpatients in Wuhan. J Allergy Clin Immunol 2020;Soo91-6749(20)30495-4.

36. New York City Health. Coronavirus Disease 2019 (COVID-19) Daily Data Summary.

https://www1.nyc.gov/assets/doh/ downloads/pdf/imm/covid-19-dailydata-summary-deaths-04152020-1.pdf. Accessed 6/1/2020.

37. Morand A, Fabre A, Minodier P, et al. COVID-19 virus and children: What do we know? Archives de Pédiatrie 2020; 27:117-118.

38. McMichael TM, Clark S, Pogosjans S, et al. COVID-19 in a long-term care facility - King County, Washington, February 27-March 9, 2020. MMWR Morb Mortal Wkly Rep 2020; 69:339-342.

39. McMichael TM, Currie DW, Clark S, et al. Epidemiology of Covid-19 in a long-term care facility in King County, Washington. N Engl J Med 2020; 382:2005-2011.

40. Grabowski DC, Joynt Maddox KE. Postacute care preparedness for COVID-19: Thinking ahead. JAMA 2020; 323:2007-2008. 
41. American Geriatrics Society (AGS) Policy Brief: COVID-19 and nursing homes.] Am Geriatr Soc 2020; 68:908-911.

42. Wang B, Li R, Lu Z, Huang Y. Does comorbidity increase the risk of patients with COVID-19: evidence from metaanalysis. Aging (Albany NY) 2020; 12:6049-6057.

43. Vardavas Cl, Nikitara K. COVID-19 and smoking: A systematic review of the evidence. Tob Induc Dis 2020;18:20.

44. Matthay MA, Zemans RL, Zimmerman $\mathrm{GA}$, et al. Acute respiratory distress syndrome. Nat Rev Dis Primers 2019; $5: 18$.

45. Fryar C, Ostchega Y, Hales C, Zhang GM, Kruszon-Moran D. Hypertension prevalence and control among adults: United States, 2015-2016. Centers for Disease Control and Prevention. NCHS Data Brief No. 289, October 2017.

https://www.cdc.gov/nchs/products/ databriefs/db289.htm Accessed 4/29/2020

46. Bozkurt B, Kovacs R, Harrington $B$. HFSA/ACC/AHA statement addresses concerns re: using RAAS antagonists in COVID-19. American Heart Association Science News.

https://professional.heart.org/ professional/ScienceNews/ UCM_505836_HFSAACCAHAstatementaddresses-concerns-re-usingRAASantagonists-in-COVID-19.jsp.\%20 March\%202020. Accessed 5/10/2020

47. Hoffmann $M$, Kleine-Weber $H$, Schroeder S, et al. SARS-CoV-2 cell entry depends on ACE2 and TMPRSS 2 and is blocked by a clinically proven protease inhibitor. Cell 2020; 181:271-280.

48. Batlle D, Wysocki J, Satchell K. Soluble angiotensin-converting enzyme 2: A potential approach for coronavirus infection therapy? Clin Sci (Lond) 2020; 134:543-545.

49. Xu Z, Shi L, Wang Y, et al. Pathological findings of COVID-19 associated with acute respiratory distress syndrome. Lancet Respir Med 2020; 8:420-422.

50. Shi S, Qin M, Shen B, et al. Association of cardiac injury with mortality in hospitalized patients with COVDI-19 in Wuhan, China. JAMA Cardiol 2020; 25:e200950.

51. World Obesity. Coronavirus (COVID-19) \& Obesity.

https://www.worldobesity.org/news/ statement-coronavirus-covid-19-obesity Accessed 6/1/2020.

52. Lighter J, Phillips M, Hochman S, et al. Obesity in patients younger than 60 years is a risk factor for Covid-19 hospital admission. Clin Infect Dis 2020; 71:896-897.

53. Simonnet A, Chetboun M, Poissy J, et al. High prevalence of obesity in severe acute respiratory syndrome coronavirus-2 (SARS-CoV-2) requiring invasive mechanical ventilation. Obesity (Silver Spring) 2020; 28:1195-1199.

54. Muniyappa R, Gubbi S. COVID-19 pandemic, coronaviruses, and diabetes mellitus. Am J Physiol Endocrinol Metab 2020; 318:E736-E741.

55. Yang JK, Feng Y, Yuan MY, et al. Plasma glucose levels and diabetes are independent predictors for mortality and morbidity in patients with SARS. Diabet Med 2006; 23:623-628.

56. Singh AK, Gupta R, Ghosh A, Misra A. Diabetes in COVID-19: Prevalence, pathophysiology, prognosis and practical considerations. Diabetes Metab Syndr 2020; 14:303-310.

57. Guo W, Li M, Dong Y, et al. Diabetes is a risk factor for the progression and prognosis of COVID-19. Diabetes Metab Res Rev 2020; 31:e3319.

58. Hill MA, Mantzoros C, Sowers JR. Commentary: COVID-19 in patients with diabetes. Metabolism 2020; 107:154217.

59. Ramos M, Khalpey Z, Lipsitz S, et al. Relationship of perioperative hyperglycemia and postoperative infections in patients who undergo general and vascular surgery. Ann Surg 2008; 248:585-591.

6o. Richards JE, Kauffmann RM, Zuckerman SL, Obremskey WT, May AK. Relationship of hyperglycemia and surgical-site infection in orthopaedic surgery. J Bone Joint Surg Am 2012; 94:1181-1186.

61. Li Z, Wu M, Yao J, et al. Caution on kidney dysfunctions of COVID-19 Patient (3/19/2020)

https://ssrn.com/abstract $=3559601$ Accessed 6/1/2020

62. Naicker S, Yang CW, Hwang SJ, Liu BC, Chen JH, Jha V. The novel coronavirus 2019 epidemic and kidneys. Kidney Int 2020; 97:824-828.

63. Li W, Moore MJ, Vasilieva $\mathrm{N}$, et al. Angiotensin-converting enzyme 2 is a functional receptor for the SARS coronavirus. Nature 2003; 426:450-454.

64. Perico L, Benigni A, Remuzzi G. Should COVID-19 concern nephrologists? Why and to what extent? The emerging impasse of angiotensin blockade.
Nephron 2020; 144:213-221

65. National Kidney Foundation. Staying safe during dialysis and the COVID-19 outbreak.

https://www.kidney.org/newsletter/ staying-safe-during-dialysis-and-covid19-outbreak\#. Accessed 4/30/2020

66. Bangash MN, Patel J, Parekh D. COVID-19 and the liver: Little cause for concern. Lancet Gastroenterol Hepatol 2020; 5:529-530.

67. Musa S. Hepatic and gastrointestinal involvement in coronavirus disease 2019 (COVID-19): What do we know till now? Arab J Gastroenterol 2020; 21:3-8.

68. Zhang Y, Zheng L, Liu L, Zhao M, Xiao J, Zhao Q. Liver impairment in COVID-19 patients: A retrospective analysis of 115 cases from a single centre in Wuhan city, China. Liver Int 2020 April 2. [Epub ahead of print].

69. Feng G, Zheng $\mathrm{KI}$, Yan QQ, et al. COVID-19 and liver dysfunction: Current insights and emergent therapeutic strategies. J Clin Transl Hepatol 2020; 8:18-24.

70. Guan WJ, Ni ZY, Hu Y, et al. Clinical characteristics of coronavirus disease 2019 in China. N Engl J Med 2020; 382:1708-1720.

71. Zhang C, Shi L, Wang FS. Liver injury in COVID-19: Management and challenges. Lancet Gastroenterol Hepatol 2020; 5:428-430.

72. Fan Z, Chen L, Li J, et al. Clinical features of COVID-19-related liver damage. Clin Gastroenterol Hepatol 2020; 18:1561-1566.

73. Guillen E, Pineiro GJ, Revuelta I, et al. Case report of COVID-19 in a kidney transplant recipient: Does immunosuppression alter the clinical presentation? Am J Transplant 2020; 20:1875-1878.

74. Fernández-Ruiz $M$, Andres $A$, Loinaz $C$, et al. COVID-19 in solid organ transplant recipients: A single-center case series from Spain. Am J Transplant 2020; 20:1849-1858.

75. Dai M, Liu D, Liu M, et al. Patients with cancer appear more vulnerable to SARSCOV-2: A multi-center study during the COVID-19 outbreak. Cancer Discov 2020; 10:783-791.

76. Rassy E, Khoury-Abboud RM, Ibrahim $\mathrm{N}$, Kattan C, Assi T, Kattan J. What the oncologist needs to know about COVID-19 infection in cancer patients. Future Oncol 2020; 16:1153-1156.

77. Joob B, Wiwanitkit V. SARS-CoV-2 and HIV. J Med Virol 2020 Mar 27. [Epub 
ahead of print].

78. Ford N, Vitoria M, Rangaraj A, Norris SL, Calmy A, Doherty M. Systematic review of the efficacy and safety of antiretroviral drugs against SARS, MERS or COVID-19: Initial assessment. J Int AIDS Soc 2020; 23:e25489.

79. D'Antiga L. Coronaviruses and immunosuppressed patients: The facts during the third epidemic. Liver Transpl 2020; 26:832-834.

8o. Al-Shamsi HO, Alhazzani W, Alhuraiji $A$, et al. A practical approach to the management of cancer patients during the novel coronavirus disease 2019 (COVID-19) pandemic: An international collaborative group. Oncologist 2020; 25:e936-eg45.

81. Connors JM, Levy JH. COVID-19 and its implications for thrombosis and anticoagulation. Blood 2020; 135:2033-2040.

82. Seitz R, Schramm W. DIC in COVID-19: Implications for prognosis and treatment? J Thromb Haemost 2020; 18:1798-1799.

83. Tang N, Li D, Wang X, Sun Z. Abnormal coagulation parameters are associated with poor prognosis in patients with novel coronavirus pneumonia. J Thromb Haemost 2020; 18:844-847.

84. Centers for Disease Control and Prevention. Evaluating and testing persons for coronavirus disease 2019 (COVID-10). https://www.cdc.gov/coronavirus/2019$\mathrm{nCoV/hcp/clinical-criteria.htm}$ Accessed 4/30/2020

85. Cheng MP, Papenburg J, Desjardins $M$, et al. Diagnostic testing for severe acute respiratory syndrome-related coronavirus-2: A narrative review. Ann Intern Med 202011:726-734.

86. He X, Lau EHY, Wu P, et al. Temporal dynamics in viral shedding and transmissibility of COVID-19. Nature Medicine 2020; 26:672-675.

87. Lei S, Jiang F, Su W, et al. Clinical characteristics and outcomes of patients undergoing surgeries during the incubation period of COVID-19 infection. EClinicalMedicine 2020; 21:100331.

88. The Antibody Society. Coronavirus in the crosshairs, part 7: Diagnostic tests. April 28, 2020.

https://www.antibodysociety.org/ antibody-validation/coronavirus-inthe-crosshairs-part-7-diagnostic-tests/ Accessed 5/28/2020

89. Burns CM. The history of cortisone discovery and development. Rheum Dis Clin North Am 2016; 42:1-14, vii.

90. Hackett BA. Providing steroid/ corticosteroid injections safely in the Covid-19 Environment. J Radiol Nurs 2020 May 3. [Epub ahead of print].

91. Coutinho AE, Chapman KE. The anti- inflammatory and immunosuppressive effects of glucocorticoids, recent developments and mechanistic insights. Mol Cell Endocrinol 2011; 335:2-13.

92. Shanthanna H, Busse J, Wang L, et al. Addition of corticosteroids to local anaesthetics for chronic non-cancer pain injections: A systematic review and meta-analysis of randomised controlled trials. Br J Anaesth 2020 Aug 12 [Epub ahead of print].

93. Sytsma TT, Greenlund LK, Greenlund LS. Joint corticosteroid injection associated with increased influenza risk. Mayo Clin Proc Innov Qual Outcomes 2018; 2:194-198.

94. Chen RC, Tang XP, Tan SY, et al. Treatment of severe acute respiratory syndrome with glucosteroids: The Guangzhou experience. Chest 2006; 129:1441-1452.

95. Han $Y$, Jiang $M$, Xia D, et al. COVID-19 in a patient with long-term use of glucocorticoids: A study of a familial cluster. Clin Immunol 2020; 214:108413.

96. Lauer SA, Grantz KH, Bi Q, et al. The incubation period of coronavirus disease 2019 (COVID-19) from publicly reported confirmed cases: Estimation and application. Ann Intern Med 2020; 172:577-582.

97. Characteristics of Health Care Personnel with COVID-19 - United States, February 12-April 9, 2020. MMWR Morb Mortal Wkly Rep 2020; 69:477-481. 

Appendix Table 1. Informed consent.

\section{Risk Disclosure for the Pain Management Procedures During the COVID-19 Pandemic}

Please review this document for relevance to your practice and edit as you see fit. This document is a modification of the Soin-Buenaventura Consent document.

Name/logo of the physician/Practice Facility OBS/ASC/Hospital:

Patient's name: Date

The novel corona virus COVID-19 has caused a global pandemic. Its clinical presentation varies from asymptomatic or mildly symptomatic, to life-threatening cardiopulmonary complications and death. Unfortunately, there is no effective treatment and a vaccine has not been developed yet. At this time, there is not enough evidence to conclusively determine whether pain management procedures have any positive or negative impact on the possibility of contracting the virus and/or development of any sequelae. Steroids are frequently used for pain injections. In high doses, steroids may have a negative effect on immunity, however, the therapeutic dose used for injections is generally low. Since COVID-19 is a new disease, and there is no conclusive evidence to suggest that injected steroids have any positive or negative effect on the COVID-19 disease, we will limit our steroid dose to the lowest effective therapeutic dose or in some cases steroids will not be injected at all. If your COVID-19 status is unknown, we cannot specifically comment on potential complications that may occur.

To reduce the risks associated with the COVID-19 infection, we are implementing safety precautions and following protocols consistent with the CDC and state recommendations. All patients and staff will be checked for fever or signs of illness upon entry to the facility. The risks, benefits, alternatives and decision to proceed with the procedure will be made in conjunction with you, the patient. However, we cannot guarantee that you will not become infected during your treatment at our practice.

By signing this written consent, you acknowledge that you have been informed about the potential risks to your health related to COVID-19 while undergoing treatments for your pain during this pandemic.

Patient's signature: Witness name:

Physician Signature: 
Appendix Table 2. Checklist for return to practice.

\begin{tabular}{|c|c|c|c|}
\hline & Yes & No & $\begin{array}{l}\text { Explanations } \\
\text { or Comments }\end{array}$ \\
\hline \multicolumn{4}{|l|}{ ASIPP/SIPMS ASC PROCEDURE SUITE OPENING CHECKLIST } \\
\hline \multicolumn{4}{|l|}{$\begin{array}{l}\text { A checklist to help you as you reopen your surgery center for elective cases during the Covid } 19 \\
\text { Pandemic: }\end{array}$} \\
\hline \multicolumn{4}{|l|}{ General: } \\
\hline \multicolumn{4}{|l|}{$\begin{array}{l}\text { Has your state opened up and allowed you to proceed with doing elective interventional pain } \\
\text { management procedures in the ASC setting? }\end{array}$} \\
\hline \multicolumn{4}{|l|}{$\begin{array}{l}\text { Has your local department of health and board of medical licensure allowed you to proceed with } \\
\text { ambulatory Surgery? }\end{array}$} \\
\hline \multicolumn{4}{|l|}{ Do you have a protocol to maintain appropriate social distancing? } \\
\hline \multicolumn{4}{|l|}{$\begin{array}{l}\text { Do you check temperatures of staff and patients and assess for symptoms of staff and patients to make } \\
\text { sure they are not likely to have COVID-19? }\end{array}$} \\
\hline \multicolumn{4}{|l|}{ Are you required to contact your local health department of opening date? } \\
\hline \multicolumn{4}{|l|}{ Have you assessed your staff for recent exposure or travel to COVID- 19 hotspots? } \\
\hline \multicolumn{4}{|l|}{ Have you trained your staff on what to do in the event of possible exposure? } \\
\hline \multicolumn{4}{|l|}{ Have the informed the following people of the plan and protocol to reopen? } \\
\hline \multicolumn{4}{|l|}{ - medical staff } \\
\hline \multicolumn{4}{|l|}{ - staff } \\
\hline \multicolumn{4}{|l|}{ - anesthesia } \\
\hline \multicolumn{4}{|l|}{ - physicians' offices/schedulers } \\
\hline \multicolumn{4}{|l|}{ - vendors } \\
\hline \multicolumn{4}{|l|}{ Will you be risk stratifying your patients? } \\
\hline \multicolumn{4}{|l|}{ Will you be disclosing the extra risks having the procedure done at this time may pose to the patient? } \\
\hline \multicolumn{4}{|l|}{$\begin{array}{l}\text { Have you confirmed the protocol to transfer the patient to a facility in the event of a complication or } \\
\text { confirmed your transfer agreement? }\end{array}$} \\
\hline \multicolumn{4}{|l|}{ Have you changed your work hours? } \\
\hline \multicolumn{4}{|l|}{ Have you updated your website if applicable due to any change in service or hours? } \\
\hline \multicolumn{4}{|l|}{ Have you had a staff meeting or training to discuss with the staff on how to handle COVID 19 cases? } \\
\hline \multicolumn{4}{|l|}{ Have you confirmed anesthesia or sedation nurse coverage if needed? } \\
\hline \multicolumn{4}{|l|}{ Is your post procedure area able to adequately provide social distancing? } \\
\hline $\begin{array}{l}\text { Did you update your cleaning policy to make sure you have properly terminally cleaned the facility and } \\
\text { have a plan in place to manage sterilization in the event of a exposure to a positive patient? }\end{array}$ & & & \\
\hline
\end{tabular}

\begin{tabular}{|c|c|c|c|}
\hline & Yes & No & $\begin{array}{l}\text { Explanations } \\
\text { or Comments }\end{array}$ \\
\hline Are the phones working properly? & & & \\
\hline Is your internet working and operational? & & & \\
\hline Have you confirmed your EMR/Charting system is ready? & & & \\
\hline Do you have a plan for biohazard waste? & & & \\
\hline Do you have adequate supply of clean linens? & & & \\
\hline Do you have adequate PPE for staff? & & & \\
\hline Are you able to provide masks to patients who request to wear one? & & & \\
\hline Have you reviewed handwashing protocol with your staff? & & & \\
\hline $\begin{array}{l}\text { Do you have signage or education to patients on frequent handwashing or infection prevention } \\
\text { recommendations? }\end{array}$ & & & \\
\hline Do you have hand sanitizing options available for patients and staff? & & & \\
\hline
\end{tabular}




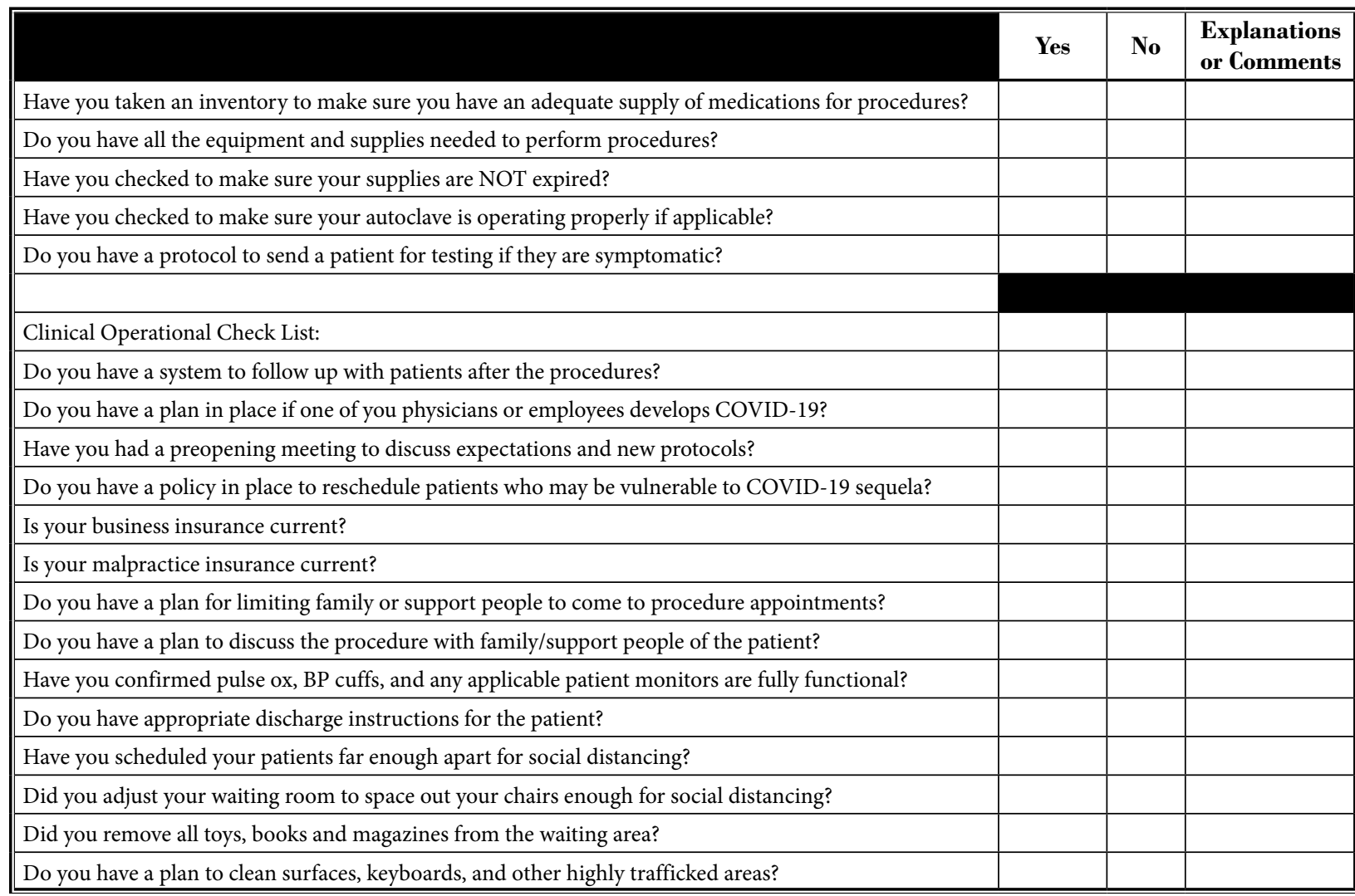

\begin{tabular}{|c|c|c|c|}
\hline & $\begin{array}{c}\text { Yes } \\
\end{array}$ & No & $\begin{array}{l}\text { Explanations } \\
\text { or Comments }\end{array}$ \\
\hline Have you informed any vendors or support staff of your opening date if needed? & & & \\
\hline Have you confirmed your staffing needs? & & & \\
\hline Do you plan to clean door knobs and other areas that are touched often? & & & \\
\hline $\begin{array}{l}\text { Do you have a plan to collect payments or copays from patients without putting the patient or staff at risk } \\
\text { for infection? }\end{array}$ & & & \\
\hline Do you plan to disclose the risk of steroids to the patient if applicable? & & & \\
\hline Does you defibrillator work properly, if applicable? & & & \\
\hline Did you confirm that your crash cart is current? & & & \\
\hline Do you have oxygen available to the patients if needed? & & & \\
\hline Do you have face shields available if applicable? & & & \\
\hline Have your staff been fit tested for N95 masks? & & & \\
\hline Is your $\mathrm{C}$-arm operational? & & & \\
\hline Do you have lead available if you plan to use X-ray? & & & \\
\hline Are you current with your radiation safety plan? & & & \\
\hline Is your operating room table functioning properly? & & & \\
\hline $\begin{array}{l}\text { Have you confirmed proper functioning of any equipment needed for patient care? Example RFA } \\
\text { machine }\end{array}$ & & & \\
\hline $\begin{array}{l}\text { Have vendors been notified of the reopening date and to see if there are any shortages that have occurred } \\
\text { due to the pandemic? }\end{array}$ & & & \\
\hline $\begin{array}{l}\text { Will you be training and discussing infection prevention with the reps and vendors who come to the } \\
\text { procedure? }\end{array}$ & & & \\
\hline
\end{tabular}

Adapted and modified from the ASCA Checklist to better meet the needs of a pain management facility. 